\title{
Gamifying a Simulation: Null Effects of a Game Goal, Choice,
}

\section{Points and Praise}

a preprint $(2017 / 08 / 22)$

(C) 2017. This manuscript version is made available under the CC-BY-NC-ND 4.0 license http://creativecommons.org/licenses/by-nc-nd/4.0/

\section{$\underline{\text { Authors }}$}

Cyril Brom

Faculty of Mathematics and Physics, Charles University

Malostranské nám. 25, 118 00, Prague, the Czech Republic

brom@ksvi.mff.cuni.cz

Tereza Stárková

Faculty of Mathematics and Physics, Charles University

Malostranské nám. 25, 118 00, Prague, the Czech Republic

tereza.starek@gmail.com

Edita Bromová

Faculty of Mathematics and Physics, Charles University

Malostranské nám. 25, 118 00, Prague, the Czech Republic

edita@email.com

Filip Děchtěrenko

Institute of Psychology, The Czech Academy of Sciences

Hybernská 8, 110 00, Prague, the Czech Republic

filip.dechterenko@gmail.com 


\section{Corresponding author}

Cyril Brom

Faculty of Mathematics and Physics, Charles University in Prague, Room 312, Malostranske Namesti 25, Prague, 11800, Czech Republic.

E-mail: brom@ksvi.mff.cuni.cz

Tel: (420) 221914 216; Fax: (420) 221914281 


\section{$\underline{\text { Abstract }}$}

Despite increased interest in gamification approaches, there is a dearth of comparative studies shedding light on the applicability of these approaches in educational contexts. This explorative study, with experimental design, sought to explore the net effects of an added game goal, increased freedom of choice, points, virtual currency and praise (all combined) on several affective-motivational variables, subjective evaluation and the learning outcomes of university learners studying a complex process from a two-hour-long computerized simulation. Learning using the simulation's version with the mentioned elements $(n=31)$ had no significant effect on initial interest, induced positive affect, flow, learning involvement, enjoyment, perceived learning, retention test scores and transfer test scores in comparison to the two control conditions $(n=33,34)$. The gamified simulation was perceived to be significantly easier than the non-gamified versions $\left(\eta_{\mathrm{p}}{ }^{2}=0.10 ; d=0.74,0.42\right)$. Of the game elements used in this study, participants perceived most positively a clear, game-like goal. The findings are consistent with Self-Determination Theory, Cognitive-Affective Theory of Learning from Media, and Cognitive Load Theory. They also support the emerging notion that caution should be taken when applying gamification approaches in educational contexts.

Keywords: gamification, serious games, simulations, motivation, learning outcomes 


\section{$\underline{\text { Article }}$}

\section{Introduction}

Gamification refers to the usage of game design elements in non-game contexts (Deterding et al., 2011). In educational settings, this means using these elements in non-game educational materials and methods (i.e., edu-gamification). Common elements include points, achievement badges and leaderboards; clear, game-like goals and increased challenges; narratives; increased freedom of choice and immediate feedback (see Darejeh and Salim, 2016; Dicheva et al., 2015). Unlike the digital game-based learning approach, which focuses on the usage of "entire" games, the gamification approach puts emphasis just on individual elements of games.

Edu-gamification approaches are posited to have motivational benefits, which are supposed to help with addressing education-relevant issues such as the increasing level of participation in online learning activities, getting familiar with a new environment (e.g., a campus or a library) or improving actual learning outcomes (e.g., Dicheva et al., 2015; Hamari et al., 2014; Hakulinen et al., 2013). However, comparative studies investigating the actual effects of a gamified educational experience compared to a control condition are rare, and the alleged claims are thus unsupported by solid empirical evidence. A vast majority of studies simply report user evaluations and/or log analyses (reviewed in Dicheva et al., 2015; Hamari et al., 2014). Much needed information is lacking about what added game design elements are beneficial or detrimental in educational settings and for what purposes. 
The majority of edu-gamification solutions pertain to mobile applications or webbased learning platforms; for instance, those used in university courses (Darejeh and Salim, 2016; Dicheva et al., 2015). It is less common to gamify stand-alone educational software, such as a computerized simulation of a complex process to be learned. Also, the majority of solutions focus on computer science and ICT topics (Dicheva et al., 2015).

This work presents an explorative, experimental study, which investigates whether a common edu-gamification approach can improve learning from a stand-alone computer simulation on a non-ICT topic. The study thus investigates edu-gamification in a new context. The game design elements in question include a game-like goal, points (which turn into virtual "money" needed for achieving the goal), increased freedom of choice and praise strengthening immediate feedback. In our study, university participants learn how to brew beer from one of the simulation's version, which takes roughly 2 hours, and their affectivemotivational states, learning outcomes and subjective evaluation are assessed and compared (i.e., between-subject design). The affective-motivational variables include initial interest and initial anxiety; induced learning involvement; induced generalized positive and negative affect; induced flow levels and enjoyment. Subjective evaluation concerns itself with perceived difficulty and perceived learning. The learning outcomes are measured in terms of immediate retention and transfer tests (Mayer, 2009) and also retention and transfer tests administered a month after the experiment. The study has the potential to indicate whether there are any advantages to employing the mentioned game elements in the service of learning from computerized applications for audiences similar to our research sample. 


\section{Background}

\subsection{Edu-gamification Studies with Comparative Design}

Gamification is a topic that has evolved rapidly over the last decade (cf. Deterding et al., 2011), and it has been applied in various contexts (see Darajeh and Salim, 2016; Dicheva et al., 2015; Hamari et al., 2014; Morschheuser et al., 2016). Gamified experiences are supposed to boost participants' engagement and motivation (see, e.g., Landers and Calan, 2011; Dicheva et al., 2015; McGonigal, 2011; Morschheuser et al., 2017; see also Darajeh and Salim, 2016) and thereby positively influence users' behavior. Gamifying educational experiences, referred to in this text as edu-gamification, can be viewed as a gamification subfield.

There is very limited knowledge about what game elements, if any, actually facilitate learning or improve other education-relevant outcomes, for what types of learners and in what contexts. Generally, edu-gamification case studies and studies with pre-post design (i.e., without control groups) have reported partly positive findings (see Dicheva et al., 2015; Hamari et al., 2014), but there is a dearth of studies with experimental or quasi-experimental design (i.e., with control groups). So far, studies with control groups have reported less positive findings than studies without control groups.

Badges and/or points with leaderboards can probably increase participation in various activities (Anderson et al., 2014; Barata et al., 2013; Denny, 2013; Halan et al., 2010; Hamari, 2017) or improve students' time management (Hakulinen et al., 2013). However, when Hanus and Fox (2015) used badges, optional "coins" and a leaderboard in one version of a university course on communication skills, they found that the gamified version did not improve students' grades and self-reported class effort. It was also detrimental to their 
intrinsic motivation, satisfaction and also partly empowerment. In a set of three studies with university students engaged in different variations of an ICT course, de-Marcos and colleagues (Domínguez et al., 2013; de-Marcos et al., 2014; de-Marcos et al., 2016) found consistently that competition-driven gamified course versions (using tasks setting short-term goals, trophies, badges and a leaderboard) helped students complete their homework assignments better (probably due to fostering motivation or better scaffolding). However, the gamified course versions hindered conceptual learning, as measured by a conceptual posttest. Only a competitive-collaborative course version, i.e., when the course was augmented both with game-based elements and a social platform, was comparable to the control condition in terms of conceptual knowledge scores and also provided benefits pertaining to homework assignments (de-Marcos et al., 2016). Also, roughly $3 / 4$ of participants in the gamified course versions rarely or never used gamified add-ons (Domínguez et al., 2013; deMarcos et al., 2014).

Wang and colleagues (2016) gamified quizzing in a university IT course (using points, leaderboards, increased time pressure, background music and improved graphics). This approach resulted in some improvements in motivation, enjoyment and engagement, but there was no difference as concerns learning gains.

Katz and colleagues (2014) engaged primary school children in working memory training by means of one of seven versions of a cognitive training application with various combinations of game-based elements. Training performance was the best when achieved points were not displayed to the learners, which also resulted in a marginally lower perceived effort. The application's version with all game-based elements was the second worst in terms of training performance. Near transfer performance, enjoyment, excitation and perceived difficulty were unaffected by the manipulations. Nevertheless, Sandberg and colleagues (2014) showed, for a similar audience, that when a gamified vocabulary learning application 
(a narrative context, a challenge specified in the terms of the narrative, achievement medals and smileys, choice) is combined with an adaptive difficulty add-on, the enhanced application's version improved home learning.

\subsection{Digital Game-based Learning Studies}

Edu-gamification is close to the domain of digital game-based learning (DGBL). One can assume that the DGBL domain might reveal which game elements facilitate learning and which do not. However, this is, by and large, not the case.

There are two major types of DGBL studies relevant for present purposes: mediacomparison ones and value-added ones (e.g., Mayer, 2014, p. 9). Media-comparison studies research whether certain new approaches to delivering educational experiences, such as using digital games, are better than a so-called "traditional" approach. Value-added studies research whether adding a particular feature to an educational experience (e.g., a game-based learning experience) enhances learning (compared to the same game without the feature).

DGBL researchers have conducted dozens of media comparison studies. These studies indicate that, on average, the DGBL approach modestly improves learning compared to "traditional" teaching methods (meta-analyzed in Sitzmann, 2011; Wouters et al., 2013; Clark et al., 2016). However, in media comparison studies, experimental and control conditions are typically very different, which brings about so many confounding variables that these studies have been criticized for comparing apples to oranges (see Clark, 2012 for a summary of the arguments).

Symptomatically, both of the most recent meta-analyses (Wouters et al., 2013; Clark et al., 2016) reported that the games' benefits attenuated when only studies with randomization were considered. This suggests that part of the "benefits" may be indeed due 
to uncontrolled differences between comparison groups. For present purposes, it is important that media comparison studies cannot easily uncover the effects of individual game elements (because the element in question is, by far, not the only difference between the experimental and the control conditions).

Because value-added studies manipulate just one or a few features of instructional materials or methods, they are better suited for investigating the effects of individual game elements. Value-added DGBL studies are on the rise. However, with the exception of enhanced scaffolding designs, they have so far been few: the Clark and colleagues' metaanalysis (2016) identified eleven of them. Their results are inconclusive (Clark et al., 2016; see also Mayer, 2014, Ch. 5). For instance, the effects of presence vs. absence of competitive elements in educational games could inform gamification research looking into the effects of competition-related elements; for instance, points, badges and leaderboards. Nevertheless, conflicting results were reported regarding the presence of competitive elements in educational games (e.g., cf. Plass et al., 2013 with Ke, 2008).

\subsection{Seductive Details}

Seductive, also called extraneous, details (e.g., Mayer, 2009) are interesting visual or auditory additions to learning materials that provide tangentially relevant information not necessary for comprehending the core instructional message. These are typically viewed as textual or visual parts aimed at increasing learners' interest. Certain game-based elements can be also viewed as seductive details in a broader sense; such as a game narrative or user interface elements added to depict the number of achieved points.

Seductive details do not improve learning in general (Garner et al., 1992; Mayer, 2009; Rey, 2012). Although they may be beneficial under some conditions (Park et al., 2015), 
one should always be prepared that the disadvantages of adding an extraneous detail to educational material may outweigh its potential benefits. For instance, the presence of a narrative (in a game-based context) was showed to be beneficial for children aged around 10 years (Cordova and Lepper, 1996; Sandberg et al., 2014) but not necessarily for college learners (Adams et al., 2012).

\subsection{Theoretical Standpoints}

The abovementioned outcomes are not surprising when cognitive-motivational theoretical perspectives are considered. First, according to the Cognitive-Affective Theory of Learning from Media (Moreno, 2005), which is a theoretical framework often used in multimedia learning, including game-based learning, a learner uses his or her cognitive resources to process incoming information. Part of these resources may remain unused, for instance, when the learner is bored. Therefore, higher motivation can enhance learning by employing more cognitive resources. However, these resources are limited. Elements of the learning environment designed to increase motivation (for example, user interface representations of points or badges) must also be processed by learners. This, according to the second theoretical framework widely used in the field, i.e., Cognitive Load Theory (Sweller et al., 2011), consumes a portion of the (limited) cognitive resources that could be otherwise devoted to processing meaningful learning content. These elements may thus function as seductive details. In addition, they may promote learning-irrelevant thinking (e.g., Pekrun and Linnenbrink-Garcia, 2012, p. 264), such as focusing the learner's attention on thoughts pertaining to increased competitive pressure. All in all, higher motivation evoked by these elements may not always enhance learning outcomes, because these elements may induce unnecessary cognitive load; deflecting the learner's attention away from the learning task. 
Second, some gaming elements, when used outside of games, may not be motivational in the first place. This idea derives from two additional theories: Self-Determination Theory (SDT) (Deci and Ryan, 1985) and Social Interdependence Theory (SIT) (Johnson and Johnson, 1989, 2009). SDT maintains that intrinsic motivation is fostered when learning environments facilitate satisfaction of learners' needs for autonomy, competence, and relatedness. Therefore, when a game element undermines one of these needs, intrinsic motivation can be reduced (see van Roy and Zaman, 2017 for a more fine-grained view of SDT in gamification contexts). SIT assumes that negative interdependence among learners hinders learning. Negative interdependence occurs in most types of social-competitive situations; i.e., when more learners compete against each other and may thus perceive that they can only achieve a goal when other individuals, against whom they are competing, fail. This may, for instance, increase their sense of social pressure, especially for learners who dislike competitive situations (cf. Brom et al., 2016), or promote cheating.

Badges, leaderboards, and points, especially, are commonly assumed to motivate and/or provide useful feedback and structure the task at hand (see, e.g., Dicheva et al., 2015; Hamari, 2017). However, they can actually be perceived by learners as expected tangible rewards. Expected tangible rewards may reduce the perception of autonomy and, according to SDT, undermine intrinsic motivation (Deci et al., 1999; but see also Cameron et al., 2001). Leaderboards also create social-competitive environments, which can (according to SIT) result in negative interdependence, hindering learning. On the more positive side, choice can enable higher control in terms of SDT and thus increase the learner's sense of autonomy, which can enhance intrinsic motivation (Patall et al., 2008). A clear goal can help structure the learning task and thereby boost, or at least not reduce, the learners' sense of competence and possibly also increase their sense of autonomy. Structuring learning (also called segmenting) can reduce cognitive load (Mayer, 2009, Ch. 9). Praise, as a verbal reward 
(Cameron et al., 2001, p. 3; Deci et al., 1999), can boost the learners' sense of competence (Vansteenkiste et al., 2009; p. 672). Badges or points, when they provide a competence feedback, can support the need for competence (van Roy and Zaman, 2017).

To summarize, individual game elements can have positive as well as negative effects in educational contexts (see Table 1). If a game element increases motivation (which is not a given), this can help allocate cognitive resources more effectively (according to CognitiveAffective Theory of Learning from Media). However, this may still not improve learning gains, because the element may impose a high unnecessary load (according to Cognitive Load Theory). For instance, it is known that despite the fact that higher freedom of choice generally increases intrinsic motivation, this does not always improve subsequent learning (Patall et al., 2008). Likewise, praise has been empirically shown to be one of the least effective types of feedback (Hattie and Timperley, 2007). Whether the positives of added game elements outweigh the negatives depends on the situation at hand. Presently, there are substantial gaps in knowledge regarding what elements (or combinations thereof) are beneficial (or detrimental or neutral) to learning; and for which types of learners and in which learning situations. 
Table 1. Effects of specific game elements according to common assumptions and three theories.

\begin{tabular}{|c|c|c|c|c|}
\hline game element & common assumptions & Cognitive Load Theory & Social Determination Theory & $\begin{array}{c}\text { Social Interdependence } \\
\text { Theory }\end{array}$ \\
\hline game goal & $\begin{array}{l}\text { enhances motivation; } \\
\text { increases challenge; } \\
\text { structures learning }(+)\end{array}$ & $\begin{array}{l}\text { if it evokes additional decision-making } \\
\text { efforts or irrelevant thoughts or is } \\
\text { connected to additional interface elements, } \\
\text { it increases unnecessary load (-); } \\
\text { structuring learning can reduce } \\
\text { unnecessary load (+) }\end{array}$ & $\begin{array}{l}\text { if it improves structuring of } \\
\text { learning activities, it can support } \\
\text { the need for competence and/or } \\
\text { autonomy }(+)\end{array}$ & \\
\hline increased choice & enhances motivation $(+)$ & $\begin{array}{l}\text { if it is accompanied by additional interface } \\
\text { elements or evokes irrelevant thoughts, it } \\
\text { increases unnecessary load (-) }\end{array}$ & supports the need for autonomy (+) & \\
\hline points, badges & $\begin{array}{l}\text { represents feedback; can } \\
\text { structure learning; enhances } \\
\text { motivation }(+)\end{array}$ & $\begin{array}{l}\text { accompanying interface elements increase } \\
\text { unnecessary load; competitive pressure can } \\
\text { evoke learning-irrelevant thoughts, } \\
\text { increasing unnecessary load }(-) ; \\
\text { structuring learning can reduce } \\
\text { unnecessary load (+) }\end{array}$ & $\begin{array}{l}\text { can undermine intrinsic motivation; } \\
\text { thwarts the need for autonomy }(-) \text {; } \\
\text { if they serve as competence } \\
\text { feedback, they can support the need } \\
\text { for competence }(+)\end{array}$ & \\
\hline $\begin{array}{l}\text { praise (as a type of verbal } \\
\text { reward) }\end{array}$ & $\begin{array}{l}\text { represents immediate } \\
\text { feedback; enhances } \\
\text { motivation }(+)\end{array}$ & $\begin{array}{l}\text { if it does not provide learning-relevant } \\
\text { information, it increases unnecessary load } \\
(-)\end{array}$ & $\begin{array}{l}\text { supports the need for competence } \\
(+)\end{array}$ & \\
\hline leaderboards & enhances motivation $(+)$ & $\begin{array}{l}\text { if present during learning session, it } \\
\text { increases unnecessary load (-) }\end{array}$ & & $\begin{array}{l}\text { can increase negative } \\
\text { interdependence }(-)\end{array}$ \\
\hline
\end{tabular}

Note: (+) sign denotes potential to enhance learning and (-) sign denotes potential to hamper learning. 


\subsection{Affective-motivational Constructs Linked to Intrinsic Motivation}

To index intrinsic motivation, we measure several positive-activating affectivemotivational variables (Pekrun and Linnenbrink-Garcia, 2012). They all relate to feelings and emotions connected to intrinsic motivation that develop within short time periods (i.e., minutes) during the learning experience undertaken. ${ }^{1}$

First, we measure triggered situational interest (hereafter called initial interest), which is usually viewed as a temporary state of concentration and enjoyment elicited by the features of a specific situation (Hidi and Renninger, 2006; Schiefele, 1999, p. 263). Second, we measure flow induced by the learning experience. Flow is typically defined as pleasant absorption during an activity that one takes part in; including increased attention to and concentration on the object of the activity to the extent of losing track of time (in its extreme form) (Csikszentmihalyi, 1975). Third, we measure learning involvement, which is also related to task concentration, but also involves positive feelings derived from learning and perceived competence. Fourth, we measure generalized positive affect, which is related to feelings of excitation, activation or enthusiasm (Watson and Tellegen, 1985). Finally, we measure enjoyment, which can be viewed as an emotional state that occurs when the activity is positively valued and is sufficiently controllable by the learner (Pekrun, 2006; p. 323). Enjoyment derives from the undergone activity per se, rather than its instrumental value.

Questionnaires for direct measurement of intrinsic motivation also exist (e.g., Isen and Reeve, 2005), but we prefer to use a broader spectrum of affective-motivational constructs

\footnotetext{
${ }^{1}$ We note here that research also investigates how these feelings and emotions influence learning when they are induced externally before the learning session starts (e.g., Plass et al., 2014) or how constructs that need more time to develop, such as academic motivation, impact in-school learning (e.g., Fortier et al., 1995). These two approaches are out of the present scope of this paper.
} 
because there are indications that some of them, such as generalized positive affect and flow, may differentially mediate learning (Brom et al., 2016). We also note that there exists a substantial overlap between items from intrinsic motivation, enjoyment, and situational interest questionnaires.

\section{This Study}

This study contributes to the existing gamification milieu in that it investigates the effects of common gamification elements in a new context (i.e., a stand-alone computer simulation on a non-ICT topic). University learners study how to brew beer: either from a gamified, roughly two-hour-long, computerized simulation or from one of two control versions of the same simulation (random assignment). The simulation is known from previous research to be motivating and to promote learning (Brom et al., 2014).

This is an exploratory study. Its primary research goal is

to investigate the net effects of several game elements on learners' affectivemotivational states induced by the learning experience, post hoc subjective evaluation and learning outcomes.

The dependent variables include

- initial interest,

- induced learning involvement,

- induced generalized positive and negative affect, 
- induced flow levels,

- induced enjoyment,

- post hoc perceived difficulty,

- post hoc perceived learning,

- retention and transfer test scores (assessed immediately),

- retention and transfer test scores (assessed after a month).

We remark that we use a research method well-established in the multimedia and digital game-based learning fields: We employ a between-subject design, with a single learning session, and focus on learning outcomes as the principal dependent variables (complemented with affective-motivational variables) (cf. Clark et al., 2016; Mayer, 2009; Mayer, 2014; Wouters et al., 2013). Delayed learning assessment is less typical, but we view long-term learning outcomes as more important than short-term ones and thus we administer the knowledge tests also a month after the intervention.

The game elements under investigation are as follows:

- a clear game goal,

- increased freedom in choice of tasks to work on,

- points given for doing well, which turn into virtual "money" needed for achieving a game goal, 
- and verbal rewards in the form of praise with some learning-related information, which strengthens immediate feedback.

These game elements were picked for ecological validity reasons: they are quite common in games and, according to our experience, often used in gamification endeavors in practice. Also, they were suggested by some learners participating in our previous study (i.e., Brom et al., 2014) as possible improvements to the (non-gamified) simulation.

Why did we not employ less or more game elements? On the one hand, it would be "purer", methodologically, to investigate the effects of a single element, but this has limited sense from practical point of view, because the elements we picked are interdependent (e.g., possibly positive effects of a clear game goal would be undermined without increased freedom of choice). On the other hand, other elements are also frequently used in practice and are thus worth investigating. However, combining too many elements in a single manipulation is methodologically problematic; complicating interpretation of findings (similar to the case of media-comparison studies discussed in Section 2.2). We thus had to compromise: instead of combining all elements worth being investigated, we picked a "minimal set" of elements such that removing a single element from the set would artificially reduce the believability of the intervention ${ }^{2}$.

We make no predictions regarding the directions of the elements' net impact because, as argued above, positive as well as negative effects can be expected (see Table 1). As

\footnotetext{
${ }^{2}$ We considered incorporating also a leaderboard, badges, and a tutor image. However, the simulation was for a single user. Therefore, were leaderboards and badges to have any meaning, they would have to have been shared across the whole experiment. Because our simulation could function believably without these features, we did not use them in this study. Also, some pilot participants suggested that we depict the tutor image (i.e., the image of the player's fictitious grandpa, as detailed in Section 4.2), but then again, the gamified simulation could function believably without it. Besides, the presence of the tutor image is a well-researched topic on its own (Mayer, 2009; see also Heidig and Clarebout, 2011). Therefore, this element was also not used here.
} 
concerns the game goal and increased choice, learners have to brew beers of several types in the last part of the simulation (in all conditions). In the gamified simulation, learners are challenged to earn money for a new fermentation vessel by selling beers made. They can also (seemingly) select beer types to brew. This should increase their sense of control and thereby motivation (possibly positive effect), but the gamification introduces new elements to the graphical interface relaying the meaning of extra information and these elements are seductive details (possibly negative effect). As concerns points, because the learning experience involves just one learner, the possible negative effects of social-competitive pressure should be avoided (i.e., there is no leaderboard; no negative interdependence among learners). There are also no tangible consequences for participants based on the amount of points they earn. In the terms of Darejeh and colleagues (2016), points represent fixed-action rewards, i.e., "they are clearly stated and users know what should be performed and what the rewards are" (p. 12). Their purpose is to be used later in the process in the form of virtual "money" to aid in achieving the game goal. Still, it is unclear if learners would perceive this type of points positively, neutrally or negatively, and if that would influence their learning in any way. Finally, praise should not undermine intrinsic motivation, as argued in Section 2.4. Even though praise is not the most effective type of feedback, it can be beneficial for learning; provided it includes learning-relevant information (which it does in our case) (see Hattie and Timperley, 2007). However, throughout the whole learning experience, users can obtain feedback about how well they are doing whenever needed by clicking on an "Assessment" button. Praise can thus be also considered to be a seductive detail (i.e., with a possibly negative effect).

This study uses two control groups, which we now discuss in detail. We previously used the simulation referred to in this study to investigate the so-called personalization principle (see Brom et al., 2014). The personalization principle states that learners should 
learn better when instructional texts are in a conversational rather than a formal style (Mayer, 2009). This principle is well supported empirically in short treatments (those up to around thirty-minutes-long) with samples from English language contexts (see Ginns et al., 2013). We have studied it in the Czech context using a long treatment, i.e., with the beer brewing simulation. We generally found no differences between the two language styles for instructional texts (Brom et al., 2014). Nevertheless, we use both conversational as well as formal simulation versions for comparison in the present study. The reason is that the language style in the conversational version was supported by a background narrative (because of the longer exposure), and the addition of a story element can itself be considered a gamification step (Dicheva et al., 2015; Hamari et al., 2014). ${ }^{3}$

Elements of all three conditions are summarized in Table 2. From the gamification perspective, the simulation's versions can be arranged on a no-game-full-fledged game spectrum as follows: non-gamified formal version < non-gamified conversational version $<$ gamified version.

Table 2. Differences between conditions.

\begin{tabular}{lll}
\hline Control 1 & Control 2 & Experimental \\
Non-gamified formal & $\begin{array}{l}\text { Non-gamified } \\
\text { conversational }\end{array}$ & Gamified \\
\hline $\begin{array}{l}\text { instructions in a formal } \\
\text { style }\end{array}$ & $\begin{array}{l}\text { instructions in a } \\
\text { conversational style, } \\
\text { simple narrative }\end{array}$ & $\begin{array}{l}\text { instructions in a } \\
\text { conversational style, simple } \\
\text { narrative } \\
\text { game goal, increased freedom } \\
\end{array}$ \\
& of choice \\
\hline
\end{tabular}

\footnotetext{
${ }^{3}$ To contrast the experimental condition with the two control conditions, we call both control conditions "nongamified", despite the fact that the conversational non-gamified condition actually features a simple narrative.
} 
praise, increased feedback

points, virtual currency

\section{Methods}

\subsection{Participants and Design}

One hundred and six Czech university students were recruited. They participated for course credit. Of these students, 98 were included in the analysis $\left(M_{\mathrm{age}}=23.05 \pm 2.53[ \pm \mathrm{SD}]\right.$; $55 \%$ males). Some multimedia learning studies recruit only psychology or educational sciences majors as participants, which limits generalizability. We therefore included participants with more diverse backgrounds (psychology, computer science, art, new media studies, and philology) by drawing from different participant pools available to us. However, we included only low prior knowledge learners, because it would have been next to impossible to recruit a sufficient number of high prior knowledge learners (as concerns beer brewing) to warrant accepting prior knowledge as a possible moderator. Specifically, participants achieving 15 or more points on a test of self-assessed prior knowledge (detailed in Section 4.4) were excluded from the analysis. In total, an additional eight participants were excluded; two for high prior knowledge of beer brewing, two for being very tired at the experiment's beginning, one for not being a Czech or Slovak native speaker ${ }^{4}$, two for not comprehending the instructions and one for not feeling well during the experiment.

\footnotetext{
${ }^{4}$ Czechoslovakia was a federation of the Czech and Slovak Republics until the end of 1992. The Slovak language is very close to the Czech language. Many Slovak students study in the Czech Republic, and it is generally no problem for Slovak university students to understand or even speak Czech fluently.
} 
The study used one experimental group (gamified, G, $n=31$ ) and two control groups (non-gamified conversational, $\mathrm{NC}, n=34$; and non-gamified formal, $\mathrm{NF}, n=33$ ), as detailed in Section 4.2. We used stratified randomization (Suresh, 2011) to achieve balanced groups with respect to gender and study background (two levels: computer science vs. others). Participants from each of four blocks (gender $\times$ study background) were assigned randomly to one of the three groups. Participants were unaware of the existence of the other conditions.

\subsection{Materials - Simulation, Framing}

The intervention is an interactive simulation originally developed by us for the purposes of our previous study (Brom et al., 2014). It was developed using the Netlogo toolkit (Wilensky, 1999). For the present experiments, three versions were used that corresponded to the study's conditions. ${ }^{5}$ All versions have four parts:

1. The tutorial, which demonstrates how to control the simulation (10-20 minutes).

2. The linear part, which demonstrates how to brew beer, when every step is done correctly (30-50 minutes).

3. The error part, which demonstrates the consequences of making errors or of not following the standard procedure as previously described (35-60 minutes).

4. The task-solving part, in which the learner brews his/her several beers of a specific type in the simulation (30-40 minutes).

The simulation is in the Czech language. All versions are self-paced. The graphical interface (Figure 1,2) includes the following elements in all three versions: textual

\footnotetext{
${ }^{5}$ During the development, we followed multimedia learning principles (Mayer, 2009) whenever possible. Also, key steps in our design process of the gamified version can be mapped onto the steps of the gamification design methodology by Morschheuser and colleagues (2017) (albeit their methodology is tailored for business domains).
} 
instructions, an animation panel showing the content of the fermentation vessels, an explanation panel relaying the meaning of graphical elements, graphs and histograms showing the amount of the ingredients in the product, an adjustable thermometer, buttons for controlling the processes, an "Assessment" button for providing immediate feedback and a slider for controlling the simulation speed. Instructional texts are depicted on individual screens; the learner can return to previous screens. The tutorial has 10 screens, the linear part 24 screens and the error part 33 screens. There are two types of instructions: process instructions that describe the beer brewing process and tutorial instructions that tell the learner what to do next. During the task-solving part, process instructions from the linear part are available to the learner (but tutorial instructions are not displayed). The number of words is as follows: the NF version: 6,138 ; the NC version: 6,750 ; the G version: 6,865 . The simulation can be controlled by several means, depending on the production phase (primarily via control buttons and adjusting temperature). Several key ingredients are (visibly) present in the product, e.g., enzymes, starch or yeast (depending on the brewing phase). The amounts of the ingredients can be monitored through graphs and histograms. When the simulation is running, this data is constantly updated and the content of the vessel is animated.

Because the learner is awarded points in the $G$ version, the simulation interface (in the G version only) also features a panel depicting the amount of points. Eventually, the learners can also sell beer produced in the $\mathrm{G}$ version and production of beer costs them virtual money. Therefore, the G version's simulation interface features additional information on the prices of various ingredients and energy consumption (these can be considered as extraneous details, but they are necessary for the gamification purposes; see Figure 2). 


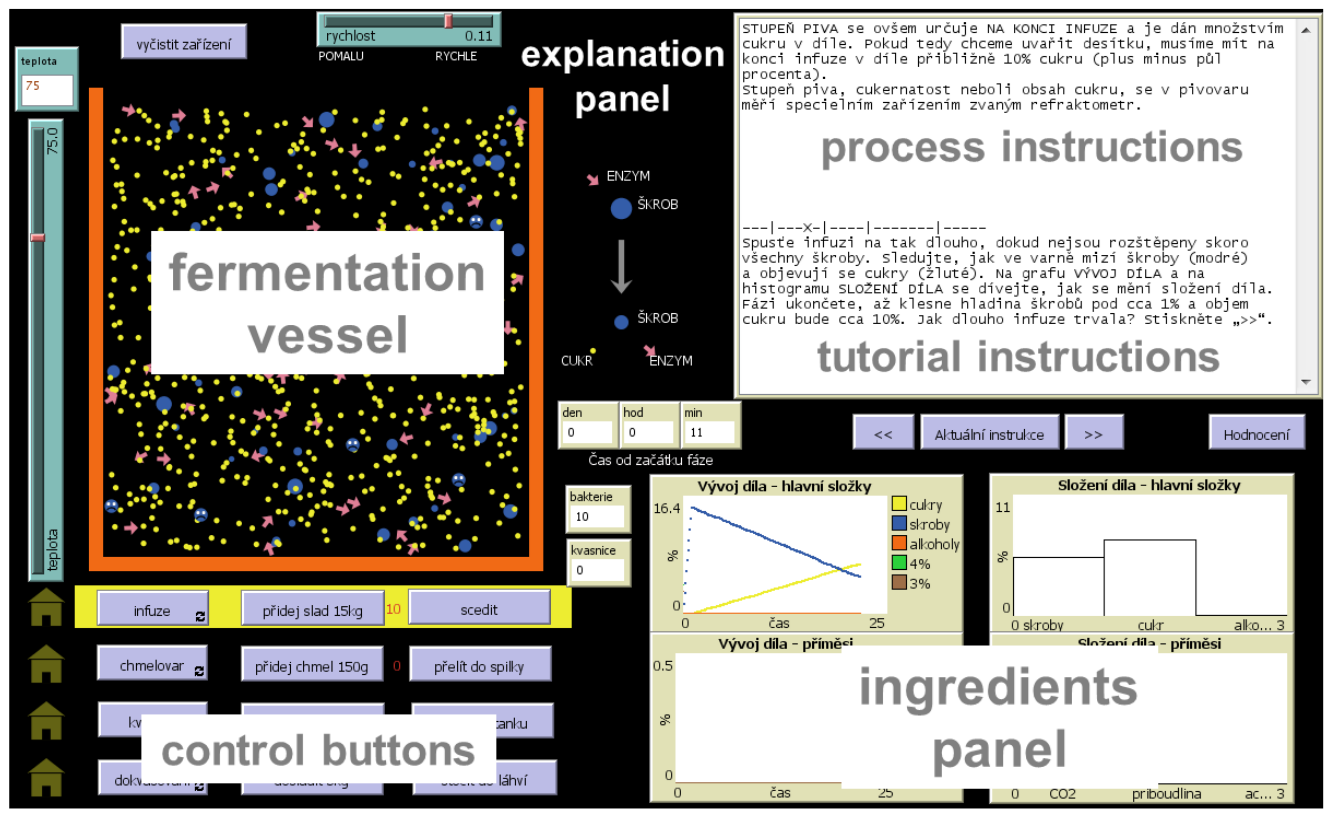

Figure 1. The simulation screenshot of the NF version. The interface is exactly the same for the NC version, except for the instructional texts (i.e., their style). Fermentation vessel, control buttons, explanation panel, instructional screens, and panels with graphs and histograms are highlighted. The slider for controlling the temperature is on the far left (set to 75 degrees Celsius). The learner can list through the instructions using the three buttons below the instructional screens. On the right side of these buttons, there is the assessment button. The slider for controlling speed and the button for starting the whole simulation are located above the fermentation vessel. All texts are in the Czech language and they are depicted for illustrative purposes only (i.e., to demonstrate the user interface's layout). 


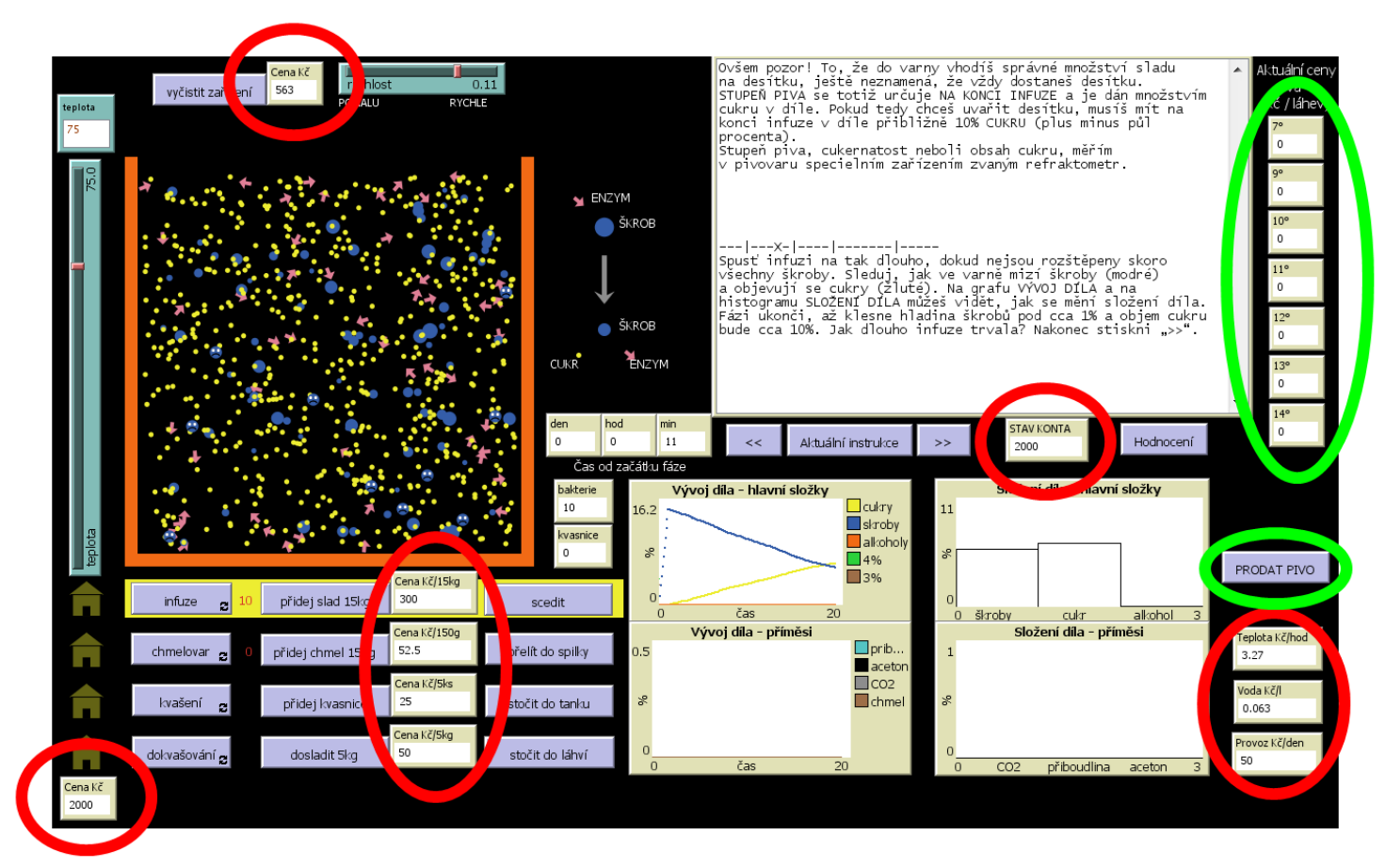

Figure 2. The simulation screenshot of the $\mathrm{G}$ version. The pricing of various ingredients, energy and water is highlighted in the color red. The wholesale price and the button for selling beer are highlighted in the color green.

In the $\mathrm{NC}$ and $\mathrm{G}$ versions, the on-screen instructions are given in a conversational style. The NF version uses a formal style (see Table 3 for an example and Brom et al., 2014 for details on how the conversational style has been operationalized). Instructional content is always the same.

To justify the usage of the conversational style for instructions in the NC and G versions, these two versions also include the following background story (taken from Brom et al., 2014), explained by the administrator at the experiment's beginning: 
Imagine you are from a family that owns a family brewery from Baroque times. After the Second World War, your grandpa was trained to become a brew master. In the fifties, the communists confiscated your family brewery, but it was returned to your family after the Velvet Revolution in the nineties. Afterwards, your grandpa ran the brewery for about 20 years, but he is now 85-years-old and he is looking for his successor. You are one of the people he has chosen to take on this role. This doesn't mean the brewery is yours: but it could be. However, your grandpa is a cautious man. He commissioned the development of a simulation modeling your family brewery. Now he will let his chosen ones interact with it the best way they know how. Only then would he allow the very best candidate to be trained at the real brewery and possibly succeed him. Your grandpa will speak to you, via textual instructions, for the duration of the simulation. Everything written in the instructions is what your grandpa would say.

The instructions are then written as if the grandpa character is speaking to the learner.

The $\mathrm{G}$ version has the following addendum to the background story:

Based on how well you accomplish tasks [given to you during the tutorial, the linear part or the error part], the grandpa character will assign you points. These points will turn into money in the final, task-solving part. In this last part, your overreaching goal will be to brew beers in order to sell them and earn money for a new fermentation vessel.

During the tutorial, the linear part and the error part, learners are given certain small tasks (e.g., to add the correct amount of malt to the fermentation vessel). There are 19 tasks in total (in each version). In the NF and NC versions, learners automatically move forward after they solve a task. Correct information is stated in the next instructional text when relevant (e.g., in case of Instruction \#6 from Table 3). In the G version, learners are additionally praised by the grandpa character and awarded points if the task has been completed correctly 
(see Table 3, Instruction \#6). The praise typically contains learning-relevant information and thus can be viewed as a form of increased immediate feedback.

When a beer of a specific type is brewed in the task-solving part, learners simply bottle the product at the end by clicking on the "bottle" button. Afterwards, learners receive the final assessment as concerns beer quality. In the NC and NF versions, they can then restart the simulation. In the G version, they can click on the "sell beer" button and sell the product (sales depend on the beer's quality). 
Table 3. Examples of two instructions from the tutorial part.

\begin{tabular}{|c|c|c|}
\hline & Instruction \#6 & Instruction \#7 \\
\hline $\begin{array}{l}\text { Process } \\
\text { instruction }\end{array}$ & $\begin{array}{l}\text { Excellent! This is exactly how I } \\
\text { imagined it. Because the brewing tank } \\
\text { holds } 1000 \text { liters of water, you had to } \\
\text { add } 150 \mathrm{~kg} \text { of malt ( } 10 \mathrm{x} 15 \mathrm{~kg}) \text { to it in } \\
\text { order to brew 10-degree beer. There is } \\
\text { the right amount of malt in the tank, } \\
\text { which means you paid attention and } \\
\text { I should therefore reward you. You } \\
\text { earn } 2000 \text { points. }\end{array}$ & $\begin{array}{l}\text { Now } \mathbf{y o u}_{\mathbf{T}} \text { heat the product to } 75 \\
\text { DEGREES Centigrade. This is the } \\
\text { temperature at which enzymes BEST } \\
\text { CONVERT starches into sugars. There are } \\
\text { also more complex methods of brewing that } \\
\text { allow for better tasting beer, but I don't use } \\
\text { them when making beer. }\end{array}$ \\
\hline $\begin{array}{l}\text { Tutorial } \\
\text { instruction }\end{array}$ & $\begin{array}{l}\text { Look }_{\mathrm{T}} \text { into the brewing tank. Starches } \\
\text { are shown inside (blue) along with } \\
\text { enzymes (pink) and bacteria (blue and } \\
\text { white). For now, the brewing tank } \\
\text { contains no sugar. Click } \\
\text { you }_{\mathrm{T}} \text {, will find out what happens } \\
\text { next. }\end{array}$ & 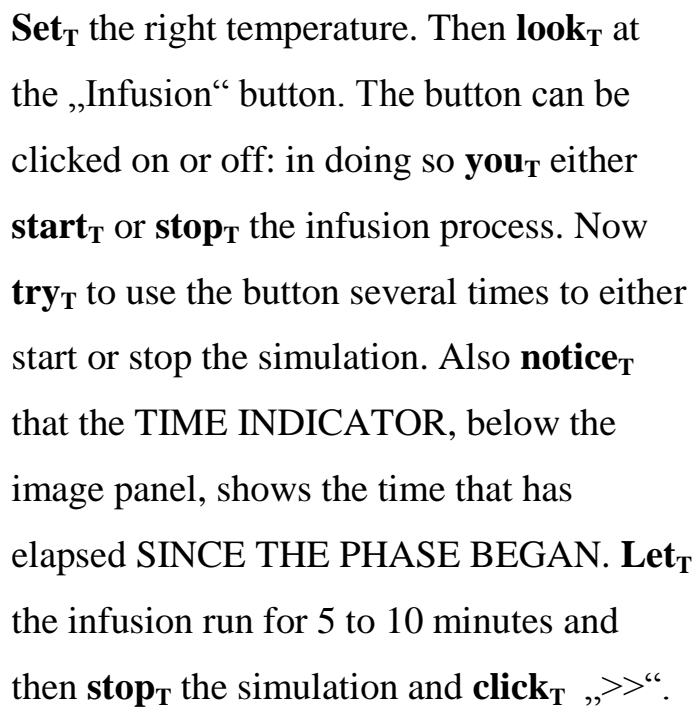 \\
\hline
\end{tabular}

Note: Some words were highlighted in the original texts using capital letters. Differences between the NF version and the other two versions are shown in boldface. Additions present only in the $\mathrm{G}$ version are in underlined boldface. Unlike the English language, the Czech language features two syntactic forms of second-person singular pronouns. One is more informal and the other more formal. Respective changes are denoted by subscript ${ }_{\mathrm{T}}$. See Brom et al. (2014) for details.

${ }^{\mathrm{a}}$ The learner added malt in the previous step. 


\subsection{Procedure}

Sessions started between 9 am and 10 am. Participants were tested in groups of 1-5 people, each sitting at a separate computer in a lab (with at least a 17"-wide screen). Each computer had two blank A4 sheets of paper and a pen in front of it. All participants from one group received the same simulation version.

The experimental schedule is depicted on Figure 3. The background narrative for the NC and G groups and the addendum about the game goal for the G group (see Section 4.2) were stated during introduction. In the control conditions, the treatment was strictly called "simulation"; whereas, it was called "game" in the G condition.

Participants were offered short breaks between the simulation parts (after filling in questionnaires associated with each part). Participants could make their own notes on the sheets of paper they received, if they so wished. They knew that their notes would be taken away for the final knowledge tests, but they could still use them during the task-solving part. 


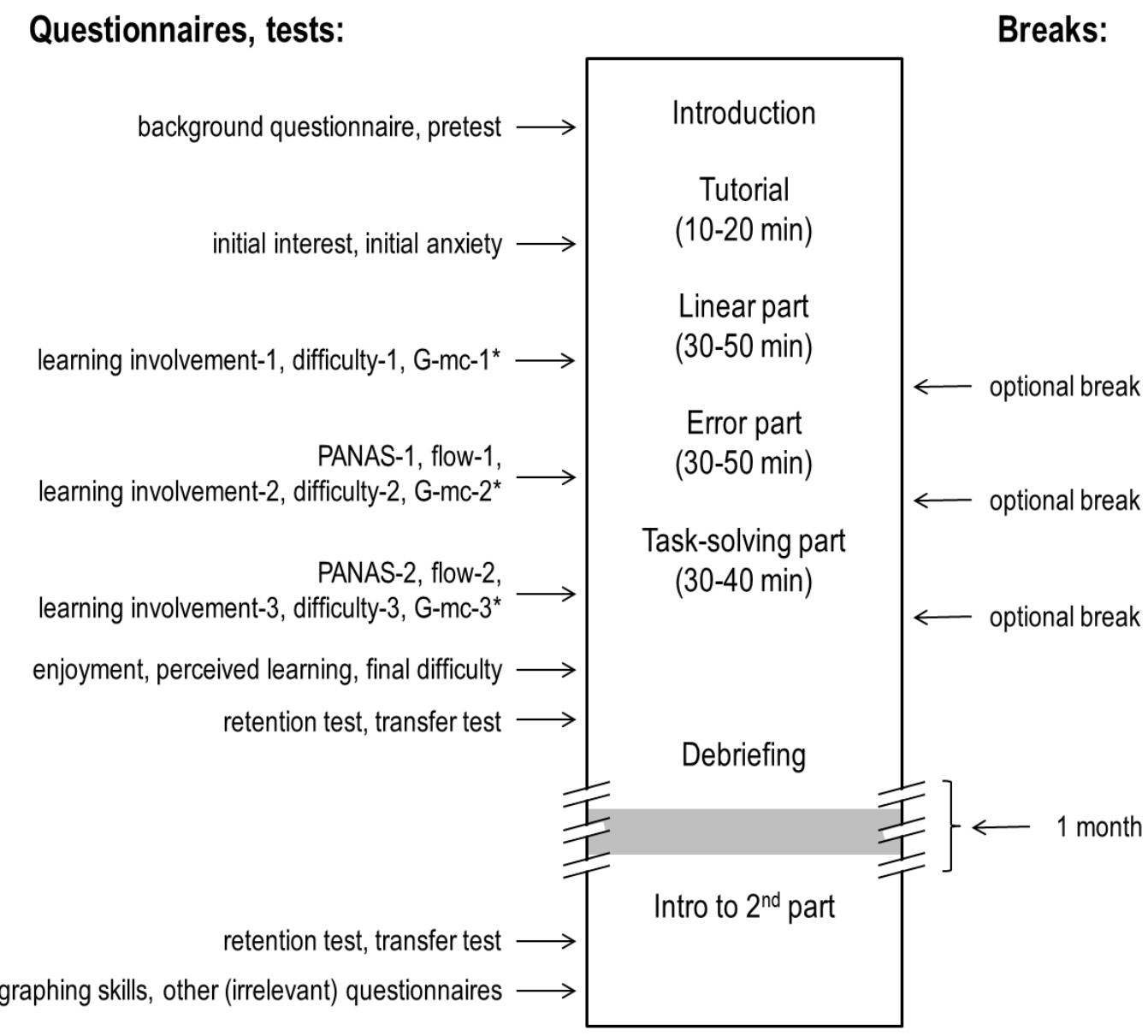

Figure 3. Schedule of the experiment. (*: G-mc = Gamified manipulation check questions)

In the task-solving part, the tasks were assigned one after another by the administrator in the control groups. The last task was assigned during the $29^{\text {th }}$ minute, at the latest, after the first task had started. The tasks were administered in the control groups in the same order. They had increasing difficulty and were as follows:

1. Please brew 13-degree beer in the simulation environment.

2. Please brew 10-degree beer that contains 5-6\% sugar (i.e., more than it normally should).

3. Please brew 11-degree beer that is spoiled (i.e., contains acetone). 
4. Please brew a drinkable 10-degree beer in less than 50 days.

No participant completed all four tasks in under less than 30 minutes.

We strived for similar hands-on experience in the gamified condition. To this end, we set the game goal (i.e., to earn a specific sum of money for a new fermentation vessel) so that it could be achieved by completing approximately 2 tasks, which is an average from the previous experiment (REMOVED-cit1) with the same task-assignment protocol. The learners could choose which beer to brew in the G condition. However, wholesale price was set for every beer type and one beer always had a better retail price due to "current market preferences", making its production more attractive for the learner. The order of beers made more attractive was the same as the order in which the participants in the control groups were assigned the tasks. In this way, the $\mathrm{G}$ group participants were primed to brew beers in the same order as control group participants did (many of them did indeed follow this order; some chose to start with a regular 10-degree beer, which is somewhat simpler compared to brewing a regular 13-degree beer). The $\mathrm{G}$ condition participants were not allowed to start a new task after 29 minutes had passed, even if they did not achieve the game goal.

We note that the game goal forces learners to calculate profit for brewed beers, which is irrelevant for the learning goal and could cause unnecessary distraction. To avoid this, we gave every $\mathrm{G}$ group participant a list with the average production costs of all typical beer types that can be brewed in the simulation (i.e., seven) when the task-solving part started. This way, the participants had only to subtract the production cost from the wholesale price in order to calculate profit.

The details of the administration of the retention and transfer tests can be found in Brom et al. (2014). The key information is that, when filling in the retention test, participants could return to previous questions, unlike in the case of the transfer test. 
At the end, participants were quickly interviewed and thanked. Around one month after the experiment, participants arrived for the delayed testing session (usually in the morning). Afterwards, they also completed a battery of psychological tests. We note that participants were informed in advance that the experiment would have two parts, but they were not informed what the content of the second part would be.

\subsection{Pen and Paper Materials}

The paper materials consisted of a background questionnaire with questions on selfassessment of prior knowledge, four affective-motivational questionnaires, a feedback questionnaire, a test on graphing in science and a retention and transfer test. All questionnaires and tests were of the pen-and-paper type.

The background questionnaire asked participants about their age, gender, study type, native language and possible vision difficulties. To check whether the groups were balanced with respect to several variables known to correlate with learning outcomes pertaining to acquisition of mental models (see Brom et al., 2014; Brom and Děchtěrenko, 2015), the background questionnaire also included one question on self-assessed knowledge of mathematics (a 6-point Likert scale) and ICT skills (a 6-point Likert scale), one question on the frequency of playing videogames (a 4-point ordinal scale), one question on the frequency of playing live action experiential/simulation games (a 5-point ordinal scale) and one question on self-assessed ability of acquiring mental models (a 7-point Likert scale). These questions are detailed in Brom et al. (2014) and Brom and Děchtěrenko (2015). For the same reasons, two questions on prior tiredness were also included: "How alert do you feel this morning?" (a 6-point Likert scale; 1 -fresh as a spring chicken; 6-very tired) and "How do 
you feel overall this morning?“ (a 6-point Likert scale; 1 -very well; 6 -very bad). An average of these two questions is denoted as an Energy variable. Likewise, the questionnaire asked one prior attitude question: "My thoughts pertaining to this experiment are" (a 7-point Likert scale; 1 -very positive; 7 - very negative).

To avoid cuing participants on what they should remember, we measured perceived domain prior knowledge rather than administering a full pre-test. From a pilot experiment, we also knew that administering full tests to naïve participants (which lasts around 30 minutes) is frustrating for them. This could influence their attitude toward the experiment and thereby the entire learning process. Perceived domain prior knowledge was thus measured as follows: 1) Participants were asked to check if any of the six questions listed apply (e.g.: "My relatives, or I personally, brew beer" or "I know what Saccharomyces cerevisiae is"). 2) Participants were meant to write down whether they had ever tried to learn about the topic of beer brewing (an open-ended question). 3) They should assess the amount of their knowledge pertaining to why and when alcohol is created during the beer brewing process (4-point ordinal scale). 4) They should answer to what extent they can explain why a morning headache can be worse when drinking non-alcoholic beer as opposed to alcoholic beer the evening before (6-point Likert scale). 5) They should indicate how often they discuss the topic of beer brewing with their friends or family (6-point Likert scale). 6) They should indicate their knowledge of beer brewing, wine-making and whiskey production (6-point Likert scale). The scale was 0 - 32. Scoring is detailed in Brom et al. (2014).

To assess initial interest, we used five questions from the Questionnaire on Current Motivation (Rheinberg et al., 2001) with a 7-point Likert scale, as we do consistently in our research (we do not use the full questionnaire's version due to time constraints). These questions were: "Today’s topic seems very interesting to me”, "I am eager to see how I will perform on today's task", "I'm really going to try as hard as I can on this task", "While doing 
this task I will enjoy discovering how to brew beer", "I would work on this task even in my free time (if I have the instructional animation)" $(\alpha=.82)$.

Our intention was also to control whether the groups were balanced with respect to initial anxiety. To assess this, we used three different questions from the same questionnaire: "When I think about the task, I feel somewhat concerned", "I'm afraid I will make a fool out of myself", "I think I won't do well at the task" $(\alpha=.81)$.

To obtain information about participants' generalized affective state, we administered PANAS (Positive and Negative Affect Schedule; Watson et al., 1988). This questionnaire consists of two 10-item mood scales: one for positive and the other for negative affect (5point Likert scale). PANAS was administered twice during the intervention (see Figure 3) with instructions "to assess one's feelings during the latest part of the simulation [the list of 20 feelings]" (positive affect: $\alpha=.87, .88$; negative affect: $\alpha=.84, .88$ ).

To obtain information about participants' flow levels, we administered the Flow Short Scale twice during the treatment (Rheinberg et al., 2003). This questionnaire measures flow experience with ten 7-point Likert items (e.g., "I do not notice time passing", "I feel I have everything under control", "I am completely lost in thought") $(\alpha=.93, .90)$.

Learning involvement was assessed three times during the treatment with a self-made questionnaire with eight 7-point Likert items. The items were inspired by various questionnaires on motivation/interest/involvement-related constructs (e.g., Schraw et al., 1995; Isen and Reeve, 2005). We use this questionnaire consistently in our research. The items were "So far, I have enjoyed brewing beer", "I always knew what to do next", "I always knew how to solve the given tasks" (for the $3^{\text {rd }}$ administration: "...how to brew particular types of beer"), "I'm tired", “I'm looking forward to the next part" (for the $3^{\text {rd }}$ administration: "I'd like to continue the beer brewing"), "I focused my mind on solving the 
given tasks" (for the $3^{\text {rd }}$ administration: “... on the beer brewing”), "I think I'm doing well so far", "I was careful and conscientious when completing the tasks" $(\alpha=.86, .88, .81)$.

Along with learning involvement questions, participants (in the same questionnaire) also rated perceived difficulty by answering the following question: "The difficulty of the simulation meets my expectations". The item had a 7-point Likert scale (1-much more difficult; 7 - much less difficult).

In the gamified condition only, participants also answered during the $1^{\text {st }}$ and $2^{\text {nd }}$ administration of the learning involvement questionnaire two manipulation check questions pertaining to the presence of added game elements: "For you personally, would it be better if the grandpa praised you" (5-point Likert scale; 1 - much more often; 5 - much less often; reverse-coded); and "For you personally, how important was it that the grandpa awarded you points". The latter question had two sub-questions with a 7-point Likert scale (a) 1 - very small/none; 7 -very large; b) 1 -very negative; 7 -very positive). These questions were replaced by the following two questions for the $3^{\text {rd }}$ administration: "For you personally, how important was it that money was part of the game" and "For you personally, how important was it that you had to achieve a game goal". Both of these questions had two sub-questions with a 7-point Likert scale (a) 1 -very small/none; 7 -very large; b) 1 -very negative; 7 very positive).

The feedback questionnaire used items with a 6-point Likert scale, and it yielded information on enjoyment induced by the whole simulation experience (two questions: "I enjoyed doing this activity", "I would describe this activity as very interesting") and perceived learning (two questions: "What knowledge do you now have of beer brewing?", "How much do you think you learned today about beer brewing?"). One question assessed overall perceived difficulty (“How difficult for you was today's lesson about beer 
brewing?"). The score from this question was averaged with scores from the three perceived difficulty questions administered during the experiment along with the learning involvement questionnaire (see above). ${ }^{6}$

The retention and transfer tests (cf. Mayer, 2009) were the same as in our previous study (Brom et al., 2014), and they were carefully piloted before that study started. Each test had two complementary versions (one for administering after the learning experience ended, one for delayed assessment; the order was counterbalanced). The retention tests had 10 shortanswer or multiple-choice questions (e.g., "Write down names of the four main phases of beer brewing in the correct order, as you learned today.", "In what phase or phases of beer brewing are enzymes present during the whole phase?") and one open-ended question ("Please explain what happens during the fermentation phase and what main products are created during this phase. Imagine you are writing a short encyclopedia entry for beginners."). The test was scored according to an exact pre-made key. The score range was 0 $-31$.

The transfer tests had 6 or 8 open-ended questions, paired across the versions (one question in the shorter version was "paired" to three questions in the longer version). Examples of questions include: "Why does the chance that the product will spoil increase, if we cannot manage a stable temperature during the whole fermentation phase? Explain in detail." or "We got rid of bacteria during the boiling phase. However, after the conditioning, the product still contains acetone (which is a product of bacteria). When and how could acetone have got into the beer? Write down every possibility you can imagine.” [emphasis always as in the original]. Each question was typed on a separate A4 sheet of paper. Participants had an allotted time to complete each question ( 2 to 5 minutes; typed above each

\footnotetext{
${ }^{6}$ We wish to remark that, even though this experiment was not part of a larger study, we also used it to pilot several questions irrelevant to the present purpose.
} 
question). The score ranges were 0 - 17 (18). Our transfer tests have an established rating system based on analysis of key "idea units" in the answers. This system generates a substantial agreement between independent raters. Nevertheless, for a check in this study, one rater scored all tests and a second independent rater pulled the tests of 22 randomly-selected participants ( $20 \%$ from the total recruited sample) and also scored them. The agreement was in the range $r=.87-1.00$ for each question, which we consider a substantial match. Scores from the first rater were used in the analysis.

A month after the intervention, participants filled in (apart from knowledge tests) a battery of psychological tests. Of these, only a test of graphing in science is relevant for present purposes. Because the simulation relayed information partly via graphs, it was important to determine whether the groups were balanced equally with respect to graphing skills. To this end, we administered a shortened version of the test on graphing in science (McKenzie and Padilla, 1986) with 9 questions, each of which could be awarded 0 or 1 point.

\subsection{Data Analysis}

Analysis was conducted in the statistical program R (R Core Team, 2016). Effect sizes were expressed either using $\eta_{\mathrm{p}}{ }^{2}$ (analysis of (co)variance) and classified into small $\left(\eta_{\mathrm{p}}{ }^{2} \sim\right.$ $0.01)$, medium $\left(\eta_{\mathrm{p}}{ }^{2} \sim 0.06\right)$ and large $\left(\eta_{\mathrm{p}}{ }^{2} \sim 0.14\right)$ effect sizes or using Cohen's $d$ (t-test) and classified into small $(d \sim 0.2)$, medium $(d \sim 0.5)$ and large $(d \sim 0.8)$ (Cohen, 1988). Flow data was transformed to T-norms provided with the standardized Flow Short Scale (Rheinberg, 2004) (final scale 21-74). Average value from transformed flow questionnaires was used. Similarly, we used average value for both generalized positive and negative affect and for learning involvement. 


\section{Results}

\subsection{Are the Groups Balanced?}

We first tested whether the groups were balanced with respect to age, energy, prior attitude towards the experiment, frequency of playing videogames and experiential games, self-assessed knowledge of mathematics and ICT, self-assessed ability of acquiring mental models, self-assessed prior knowledge, initial anxiety, graphing skills and time spent on intervention (Table 4). The groups were balanced with respect to all variables, except for age. This variable correlates with several dependent variables (Table 5), and we thus include it as a covariate for the main analysis. 
Table 4. Control variables: means, standard deviations in brackets and ANOVA results.

\begin{tabular}{|c|c|c|c|c|c|c|c|}
\hline \multirow[t]{2}{*}{ Variable } & \multicolumn{3}{|c|}{ Condition } & \multicolumn{4}{|c|}{ ANOVA $^{\mathrm{a}, \mathrm{b}}$} \\
\hline & NF & $\mathrm{NC}$ & G & $\mathrm{F}$ & $d f$ & $\eta_{\mathrm{p}}^{2}$ & $\begin{array}{c}95 \% \mathrm{CI} \\
\eta^{2}\end{array}$ \\
\hline age & $23.09(2.48)$ & $22.29(1.87)$ & $23.84(3.00)$ & $3.16^{*}$ & 2,95 & 0.06 & {$[0,0.16]$} \\
\hline energy & $3.33(1.45)$ & $2.85(1.35)$ & $2.69(1.15)$ & 1.97 & 2,91 & 0.04 & {$[0,0.12]$} \\
\hline prior attitude & $2.82(1.16)$ & $2.88(1.15)$ & $2.44(0.93)$ & 1.35 & 2,91 & 0.03 & {$[0,0.09]$} \\
\hline freq. videogames & $1.70(0.88)$ & $1.76(1.07)$ & $1.87(0.96)$ & 0.26 & 2,95 & 0.01 & {$[0,0.02]$} \\
\hline freq. exp. games & $2.30(1.29)$ & $2.32(1.07)$ & $2.13(0.88)$ & 0.30 & 2,95 & 0.01 & {$[0,0.03]$} \\
\hline math knowledge & $4.39(1.48)$ & $4.44(1.19)$ & $4.29(1.37)$ & 0.11 & 2,95 & 0.00 & {$[0,0.01]$} \\
\hline ICT knowledge & $4.76(1.30)$ & $4.79(1.12)$ & $4.9(1.16)$ & 0.13 & 2,95 & 0.00 & {$[0,0.01]$} \\
\hline mental models & $5.82(1.67)$ & $5.82(1.68)$ & $5.48(1.96)$ & 0.38 & 2,95 & 0.01 & {$[0,0.04]$} \\
\hline initial anxiety & $9.00(5.01)$ & $9.53(4.88)$ & $9.30(4.11)$ & 0.11 & 2,94 & 0.00 & {$[0,0.01]$} \\
\hline graphing skills & $5.82(2.34)$ & $6.65(2.14)$ & $6.80(2.04)$ & 1.89 & 2,94 & 0.04 & {$[0,0.13]$} \\
\hline \multirow{2}{*}{ time on task } & 126.92 & 132.40 & 130.40 & 0.52 & 2,95 & 0.01 & {$[0,0.05]$} \\
\hline & $(23.23)$ & (22.66) & (20.35) & & & & \\
\hline self-assessed & $3.61(3.47)$ & $4.40(2.85)$ & $4.52(3.99)$ & 0.67 & 2,95 & 0.01 & {$[0,0.05]$} \\
\hline prior knowledge & & & & & & & \\
\hline
\end{tabular}

${ }^{\mathrm{a}}$ Test assumptions of homogeneity were met, except for age (Bartlett's test: $p=.033$ ) but ANOVAs are robust to the homogeneity violation as long as groups are of roughly equal size (Bathke, 2004). This is the present case. The normality assumption was violated for all variables (Shapiro-Wilk test: $p$ s <.05). ANCOVAs are robust to the normality violation (Levy, 1980), but the results can be biased if normality is violated due to the presence of outliers (see Stevens, 2012). We detected one outlier for age (Grubb's test: $p=.013$ ) and reran the test with the outlier removed. A marginally significant difference was still detected ( $p$ $=.092)$. We also re-ran all tests using a non-parametric Kruskal-Wallis test: no significance changed (age: $p=.045$; other $p$ s $>.156$ ).

${ }^{\mathrm{b}}$ The confidence interval for $\eta_{p}{ }^{2}$ was computed using a bootstrapping technique $(N=1000)$. 
Table 5. Correlation matrix (Pearson's $r$ ). The number in brackets denotes the number of observations used for correlation.

\begin{tabular}{|c|c|c|c|c|c|c|c|c|c|c|c|c|}
\hline & age & $\begin{array}{l}\text { initial } \\
\text { interest }\end{array}$ & $\begin{array}{l}\text { learning } \\
\text { involveme } \\
\text { nt }\end{array}$ & $\begin{array}{l}\text { positive } \\
\text { affect }\end{array}$ & $\begin{array}{l}\text { negative } \\
\text { affect }\end{array}$ & flow & enjoyment & $\begin{array}{l}\text { perceived } \\
\text { learning }\end{array}$ & $\begin{array}{l}\text { perceived } \\
\text { difficulty }\end{array}$ & $\begin{array}{l}\text { retention } \\
\text { test - } \\
\text { immed. }\end{array}$ & $\begin{array}{l}\text { retention } \\
\text { test - } \\
\text { delayed }\end{array}$ & $\begin{array}{l}\text { transfer } \\
\text { test - } \\
\text { immed. }\end{array}$ \\
\hline initial interest & $\begin{array}{l}-0.09 \\
(98)\end{array}$ & - & & & & & & & & & & \\
\hline $\begin{array}{l}\text { learning } \\
\text { involvement }\end{array}$ & $\begin{array}{l}-0.04 \\
(98)\end{array}$ & $\begin{array}{l}0.65^{* * *} \\
(98)\end{array}$ & - & & & & & & & & & \\
\hline positive affect & $\begin{array}{l}-0.19 \dagger \\
(98)\end{array}$ & $\begin{array}{l}0.52 * * * \\
(98)\end{array}$ & $\begin{array}{l}0.64 * * * \\
(98)\end{array}$ & - & & & & & & & & \\
\hline $\begin{array}{l}\text { negative } \\
\text { affect }\end{array}$ & $\begin{array}{l}-0.07 \\
(98)\end{array}$ & $\begin{array}{l}0.05 \\
(98)\end{array}$ & $\begin{array}{l}-0.29 * * \\
(98)\end{array}$ & $\begin{array}{l}0.03 \\
(98)\end{array}$ & - & & & & & & & \\
\hline flow & $\begin{array}{l}0.01 \\
(95)\end{array}$ & $\begin{array}{l}0.48^{* * * *} \\
(95)\end{array}$ & $\begin{array}{l}0.83 * * * \\
(95)\end{array}$ & $\begin{array}{l}0.62 * * * \\
(95)\end{array}$ & $\begin{array}{l}-0.38 * * * \\
(95)\end{array}$ & - & & & & & & \\
\hline enjoyment & $\begin{array}{l}-0.27 * * a \\
(98)\end{array}$ & $\begin{array}{l}0.56^{* * * *} \\
(98)\end{array}$ & $\begin{array}{l}0.67 * * * \\
(98)\end{array}$ & $\begin{array}{l}0.62 * * * \\
(98)\end{array}$ & $\begin{array}{l}-0.12^{\mathrm{a}} \\
(98)\end{array}$ & $\begin{array}{l}0.60 * * * \\
(95)\end{array}$ & - & & & & & \\
\hline $\begin{array}{l}\text { perceived } \\
\text { learning }\end{array}$ & $\begin{array}{l}-0.29 * * a \\
(98)\end{array}$ & $\begin{array}{l}0.34 * * * \\
(98)\end{array}$ & $\begin{array}{l}0.37 * * * \\
(98)\end{array}$ & $\begin{array}{l}0.45^{* * *} \\
(98)\end{array}$ & $\begin{array}{l}0.05 \\
(98)\end{array}$ & $\begin{array}{l}0.25^{*} \\
(95)\end{array}$ & $\begin{array}{l}0.42^{* * *} \\
(98)\end{array}$ & - & & & & \\
\hline $\begin{array}{l}\text { perceived } \\
\text { difficulty }\end{array}$ & $\begin{array}{l}-0.12 \\
(94)\end{array}$ & $\begin{array}{l}-0.24 * \\
(94)\end{array}$ & $\begin{array}{l}-0.41 * * * \\
(94)\end{array}$ & $\begin{array}{l}-0.17 \\
(94)\end{array}$ & $\begin{array}{l}0.25^{*} \\
(94)\end{array}$ & $\begin{array}{l}-0.40 * * * \\
(91)\end{array}$ & $\begin{array}{l}-0.16 \\
(94)\end{array}$ & $\begin{array}{l}-0.07 \\
(94)\end{array}$ & - & & & \\
\hline $\begin{array}{l}\text { retention test } \\
- \text { immediate }\end{array}$ & $\begin{array}{l}0.02 \\
(98)\end{array}$ & $\begin{array}{l}0.18 \dagger \\
(98)\end{array}$ & $\begin{array}{l}0.36^{* * *} \\
(98)\end{array}$ & $\begin{array}{l}0.23 * \\
(98)\end{array}$ & $\begin{array}{l}-0.19 \dagger \\
(98)\end{array}$ & $\begin{array}{l}0.31 * * \\
(95)\end{array}$ & $\begin{array}{l}0.10 \\
(98)\end{array}$ & $\begin{array}{l}0.10 \\
(98)\end{array}$ & $\begin{array}{l}-0.30 * * \\
(94)\end{array}$ & - & & \\
\hline $\begin{array}{l}\text { retention test } \\
\text { - delayed }\end{array}$ & $\begin{array}{l}0.20 \dagger \\
(97)\end{array}$ & $\begin{array}{l}0.32 * * \\
(97)\end{array}$ & $\begin{array}{l}0.37 * * * \\
(97)\end{array}$ & $\begin{array}{l}0.25^{*} \\
(97)\end{array}$ & $\begin{array}{l}-0.16 \\
(97)\end{array}$ & $\begin{array}{l}0.40^{* * * *} \\
(94)\end{array}$ & $\begin{array}{l}0.11 \\
(97)\end{array}$ & $\begin{array}{l}0.13 \\
(97)\end{array}$ & $\begin{array}{l}-0.41 * * * \\
(93)\end{array}$ & $\begin{array}{l}0.55^{* * *} \\
(97)\end{array}$ & - & \\
\hline $\begin{array}{l}\text { transfer test - } \\
\text { immediate }\end{array}$ & $\begin{array}{l}0.13 \\
(96)\end{array}$ & $\begin{array}{l}0.08 \\
(96)\end{array}$ & $\begin{array}{l}0.26^{*} \\
(96)\end{array}$ & $\begin{array}{l}0.18 \dagger \\
(96)\end{array}$ & $\begin{array}{l}-0.14 \\
(96)\end{array}$ & $\begin{array}{l}0.27 * * \\
(94)\end{array}$ & $\begin{array}{l}0.13 \\
(96)\end{array}$ & $\begin{array}{l}0.05 \\
(96)\end{array}$ & $\begin{array}{l}-0.31 * * \\
(92)\end{array}$ & $\begin{array}{l}0.60 * * * \\
(96)\end{array}$ & $\begin{array}{l}0.55^{* * * *} \\
(95)\end{array}$ & - \\
\hline $\begin{array}{l}\text { transfer test - } \\
\text { delayed }\end{array}$ & $\begin{array}{l}0.33 * * \\
(96)\end{array}$ & $\begin{array}{l}0.22 * \\
(96)\end{array}$ & $\begin{array}{l}0.31 * * \\
(96)\end{array}$ & $\begin{array}{l}0.18 \dagger \\
(96)\end{array}$ & $\begin{array}{l}-0.07 \\
(96)\end{array}$ & $\begin{array}{l}0.30^{* * *} \\
(93)\end{array}$ & $\begin{array}{l}0.05 \\
(96)\end{array}$ & $\begin{array}{l}0.02 \\
(96)\end{array}$ & $\begin{array}{l}-0.36 * * * \\
(92)\end{array}$ & $\begin{array}{l}0.45^{* * * *} \\
(96)\end{array}$ & $\begin{array}{l}0.67 * * * \\
(96)\end{array}$ & $\begin{array}{l}0.61 * * * \\
(94)\end{array}$ \\
\hline
\end{tabular}

$\dagger p<.1 ; * p<.05 ; * * p<.01 ; * * * p<.001$ 
${ }^{a}$ Spearman's rank correlation coefficients are similar, with the following notable exceptions: $\rho$ (enjoyment, age) $=-.18 \dagger ; \rho$ (enjoyment, negative affect $)=-.20 * ; \rho($ perceived learning, age $)=-.18 \dagger$. 


\subsection{Is Gamification Noticed by Participants?}

Second, we tested whether participants in the G condition reported that they noticed the gamification elements at all. These tests serve as manipulation checks. The data (Table 6) indicate that while a few participants were probably oblivious to the gamification, the game design elements had some relevance for the majority of them. The game goal received the best assessment: both in terms of importance as well as valence. However, virtual money and points were also perceived positively. As concerns praise, participants reported that they were satisfied with the amount of praise given.

Table 6. Manipulation check variables: means, standard deviations and one-sample t-test for deviation from the midpoint as concerns valence.

\begin{tabular}{|c|c|c|c|c|c|}
\hline Variable & Scale & $\begin{array}{l}\text { Neutral } \\
\text { midpoint }\end{array}$ & Mean (SD) & $t^{\mathrm{d}}$ & $d f$ \\
\hline praise & $1-5^{\mathrm{a}}$ & 3 & $3.06(0.42)$ & 0.68 & 26 \\
\hline \multicolumn{6}{|l|}{ points } \\
\hline - importance & $1-7^{\mathrm{b}}$ & - & $4.89(1.51)$ & - & - \\
\hline - valence & $1-7^{\mathrm{c}}$ & 4 & $5.73(1.15)$ & $7.97 * * *$ & 27 \\
\hline \multicolumn{6}{|l|}{ money } \\
\hline - importance & $1-7^{\mathrm{b}}$ & - & $4.39(1.93)$ & - & - \\
\hline - valence & $1-7^{\mathrm{c}}$ & 4 & $5.06(1.12)$ & $5.28 * * *$ & 30 \\
\hline \multicolumn{6}{|l|}{ goal } \\
\hline - importance & $1-7^{b}$ & - & $6.23(0.84)$ & - & - \\
\hline - valence & $1-7^{\mathrm{c}}$ & 4 & $6.00(0.93)$ & $11.96 * * *$ & 30 \\
\hline \multicolumn{6}{|l|}{$* * * p<.001$} \\
\hline \multicolumn{6}{|c|}{${ }^{\mathrm{a}} 1$ - much less; 5 - much more } \\
\hline \multicolumn{6}{|c|}{${ }^{\mathrm{b}} 1$ - very small/none; 7 - very large } \\
\hline
\end{tabular}

${ }^{\mathrm{d}}$ Because normality assumptions were violated $(p \mathrm{~s}<.003)$, we re-ran the tests using Wilcoxon Signed-Rank test. No significance changed (praise: $p=.596$; other $p$ s $<.001$ ). 


\subsection{Are there any Effects of Gamification?}

Descriptive data are included in Table 7. Because the key positive affectivemotivational variables (i.e., initial interest, learning involvement, positive affect, flow, enjoyment) and four test score variables (i.e., retention immediate and delayed, and transfer immediate and delayed) were inter-correlated (Table 5), we analyzed the effects of gamification on these variables using MANCOVAs with age as a covariate. There were no differences between groups (Pillai test; affective-motivational variables: $F(10,172)=0.98 ; p$ $=.460$; learning outcomes: $\left.F(4,360)=0.97 ; p=.425^{7}\right)$.

We analysed between-group differences for the remaining dependent variables using ANCOVAs with age as a covariate. A significant difference was detected as concerns perceived difficulty $\left(F(2,88)=4.76, p=.011 ; \eta_{\mathrm{p}}{ }^{2}=.10 ; 95 \% \mathrm{CI}[.02, .20]\right)$, and no significant difference as concerns negative affect $\left(F(2,92)=0.39, p=.676 ; \eta_{\mathrm{p}}{ }^{2}=.01 ; 95 \%\right.$ CI $[.00, .04])$ and perceived learning $\left(F(2,92)=0.52, p=.597 ; \eta_{\mathrm{p}}{ }^{2}=.01 ; 95 \%\right.$ CI $\left.[.00, .05]\right)$. For perceived difficulty, post hoc tests showed that the experience was perceived as easier in the gamified group compared to non-gamified formal group (Tukey's test; $t(60)=2.9 ; p=$ $.013 ; d=0.74 ; 95 \% \mathrm{CI}[0.21,1.27])$. The difference also tended in the same direction as

\footnotetext{
${ }^{7}$ Assumptions for multivariate normality, homogeneity of variance, and homogeneity of variance-covariance matrices were met for MANCOVA that concerned test scores. Assumptions for the affective-motivational MANCOVA were also met, except for the normality assumption. However, MANCOVAs are robust with respect to deviances from the normal distribution (Olson, 1974). We also tested between-group differences for individual variables using a) ANCOVA with age as a covariate (on the whole sample), b) ANCOVA with age as a covariate (with outliers removed), and c) a non-parametric Kruskal-Wallis test. No significant difference was detected using any of the tests (all $p \mathrm{~s}>.159$ ).
} 
concerns the non-gamified conversational group; and in the medium range, though not significant $(t(61)=1.64 ; p=0.234 ; d=0.42 ; 95 \%$ CI $[-0.10,0.93]){ }^{8}$

Even at a purely descriptive level, there were no consistent advantages (or disadvantages) for the gamified simulation's version. ${ }^{9}$ Apparently, the effects of the gamification were very limited. Because of this, we did not move forward with the analysis of whether the effects of gamification on learning outcomes are mediated by affectivemotivational variables.

We also explored whether or not participants' study background (computer science vs. others, i.e., primarily social sciences) is a moderator. Two-way ANCOVAs with age as a covariate and participants' background as a factor, showed that across the whole sample computer science students consistently outperformed other students in all tests $(p s<.002)$; were more interested after the tutorial $(p=.003)$; their induced positive affect, flow, enjoyment and learning involvement were higher $(p<.035)$; and they perceived the simulation to be easier $(p=.001)$. Only for negative affect $(p=.263)$ and perceived learning $(p=.212)$, was no significant difference between the two groups of learners detected. However, condition $\times$ study background interaction was not significant for any of the dependent variables $(p s>$.118). Descriptively, there appears to be some interactions; the most salient one being for negative affect, such that induced negative affect was lower for computer science students, but only in the non-gamified conditions (see Table 7). These

\footnotetext{
${ }^{8}$ Test assumptions of homogeneity were met (Bartlett's test: $p s>.140$ ). Test assumptions of normality were violated for perceived learning and negative affect $(p s<.001)$. ANCOVAs are robust with respect to the normality violation (Levy, 1980), but the results can be biased if normality is violated due to the presence of outliers (see Stevens, 2012). The results did not change when the analysis was re-run with outliers removed (perceived difficulty: $p=.018$; other variables: $p$ s $>.724$ ), or when the data were analyzed using a KruskalWallis test (perceived difficulty: $p=.019$; other variables: $p$ s $>.210$ ).

${ }^{9}$ Also, because there were no significant between-group differences between the two control conditions in any of the dependent variables (all $p \mathrm{~s}>.103$ for two-sample t-tests), one can analyze differences between the $\mathrm{G}$ condition and the combined control conditions (we are aware of the unequal sample sizes in these tests). Again, there was no between-group difference (t-test: $p \mathrm{~s}>.147$; Wilcoxon signed-rank test: $p \mathrm{~s}>.114$ ) except for a medium to large effect on the perceived difficulty $(t(92)=-3.11 ; p=.003 ; d=-0.67,95 \%$ CI $[-1.12,-0.23] ; W$ $=625 ; p=.009$ ).
} 
apparent, non-significant interactions are either noise or missed true effects due to a relatively small number of participants per cell $(\sim 16)$. 
Table 7. Means and SDs for participants split based on their study background.

\begin{tabular}{|c|c|c|c|c|c|c|c|c|c|}
\hline \multirow[t]{3}{*}{ Variable } & \multicolumn{9}{|c|}{ Condition } \\
\hline & \multicolumn{3}{|c|}{ NF } & \multicolumn{3}{|c|}{$\mathrm{NC}$} & \multicolumn{3}{|c|}{ G } \\
\hline & All students & $\begin{array}{l}\text { Computer } \\
\text { science }\end{array}$ & Others & All students & $\begin{array}{l}\text { Computer } \\
\text { science }\end{array}$ & Others & All students & $\begin{array}{l}\text { Computer } \\
\text { science }\end{array}$ & Others \\
\hline$n$ & 33 & 17 & 16 & 34 & 17 & 17 & 31 & 16 & 15 \\
\hline initial interest & $26.58(5.07)$ & $28.00(4.49)$ & $25.06(5.36)$ & $25.68(5.13)$ & $27.41(5.04)$ & $23.94(4.75)$ & $27.68(4.48)$ & $28.50(4.15)$ & $26.80(4.78)$ \\
\hline $\begin{array}{l}\text { learning } \\
\text { involvement }\end{array}$ & $44.71(5.89)$ & $48.02(4.26)$ & $41.18(5.37)$ & $45.29(6.63)$ & $47.53(6.87)$ & $43.06(5.73)$ & $46.61(5.53)$ & $48.71(3.98)$ & $44.36(6.17)$ \\
\hline positive affect & $30.20(5.88)$ & $31.41(5.47)$ & $28.91(6.20)$ & $32.82(7.03)$ & $33.35(7.21)$ & $32.29(7.02)$ & $32.26(7.49)$ & $34.47(7.44)$ & $29.90(7.03)$ \\
\hline negative affect & $13.71(3.76)$ & $12.71(2.76)$ & $14.78(4.43)$ & $14.53(5.28)$ & $13.06(4.56)$ & $16.00(5.67)$ & $13.45(4.22)$ & $14.22(5.50)$ & $12.63(2.10)$ \\
\hline flow & $54.11(8.28)$ & $57.21(6.56)$ & $50.60(8.83)$ & $56.27(8.28)$ & $59.94(8.39)$ & $52.59(6.53)$ & $57.23(7.33)$ & $60.22(4.64)$ & $54.03(8.41)$ \\
\hline enjoyment & $4.85(0.98)$ & $5.06(0.63)$ & $4.62(1.23)$ & $4.88(0.78)$ & $5.03(0.70)$ & $4.74(0.85)$ & $4.94(0.87)$ & $5.09(0.76)$ & $4.77(0.98)$ \\
\hline perceived learning & $4.52(0.89)$ & $4.53(1.04)$ & $4.50(0.73)$ & $4.66(0.80)$ & $4.68(0.90)$ & $4.65(0.70)$ & $4.65(0.89)$ & $4.84(0.81)$ & $4.43(0.94)$ \\
\hline $\begin{array}{l}\text { perceived difficulty } \\
\text { retention test }\end{array}$ & $3.45(0.64)$ & $3.21(0.51)$ & $3.70(0.67)$ & $3.30(0.53)$ & $3.13(0.36)$ & $3.47(0.64)$ & $2.96(0.62)$ & $2.74(0.71)$ & $3.23(0.37)$ \\
\hline - immediate & $24.72(5.11)$ & $26.74(3.13)$ & $22.58(5.98)$ & $25.53(4.07)$ & $26.82(3.42)$ & $24.24(4.35)$ & $24.82(3.43)$ & $25.55(2.65)$ & $24.05(4.06)$ \\
\hline $\begin{array}{l}\text { - delayed } \\
\text { transfer test }\end{array}$ & $17.78(6.37)$ & $20.24(5.15)$ & $15.17(6.65)$ & $18.62(6.40)$ & $21.24(6.50)$ & $16.00(5.27)$ & $19.88(5.60)$ & $21.59(5.74)$ & $17.93(4.92)$ \\
\hline - immediate & $0.27(0.96)$ & $0.52(0.66)$ & $-0.02(1.17)$ & $0.53(0.82)$ & $0.93(0.77)$ & $0.12(0.67)$ & $0.18(0.88)$ & $0.55(0.88)$ & $-0.19(0.72)$ \\
\hline - delayed & $-0.48(0.89)$ & $-0.12(0.75)$ & $-0.89(0.87)$ & $-0.29(1.01)$ & $0.17(1.17)$ & $-0.74(0.55)$ & $-0.22(1.09)$ & $0.31(0.92)$ & $-0.84(0.96)$ \\
\hline
\end{tabular}

Note: higher values mean "more", including perceived difficulty (more difficult) and negative affect (a higher negative affect). 


\section{Discussion and Conclusion}

This study sought to explore the net effects of an added game goal, increased freedom of choice, points, virtual currency and praise (all combined) on positive affectivemotivational states, subjective evaluation and learning outcomes for college learners studying a complex process in a computerized simulation. In doing so, the study investigated edugamification in a new context. Neither beneficial nor detrimental effects of these gamification elements on retention and transfer test scores, initial interest, induced positive affect, flow, learning involvement and enjoyment were revealed. The only significant difference between the gamified simulation and the non-gamified simulation's versions was in perceived difficulty. The gamified simulation was perceived to be easier compared to the non-gamified versions. For all dependent variables, participants' background (i.e., students of computer science vs. social sciences and art) was not found to be a significant moderator. Of the game elements used in this study, participants perceived a clear game-like goal most positively.

\subsection{Theoretical Perspectives}

In this paper, we have presented an integrated view on how Self-Determination Theory (SDT) (Deci and Ryan, 1985), Social Interdependence Theory (Johnson and Johnson, 1989), Cognitive-Affective Theory of Learning from Media (Moreno, 2005), and Cognitive Load Theory (Sweller et al., 2011) together predict how several key game elements influence learners' intrinsic motivation, unnecessary cognitive load, and learning outcomes in edugamification contexts (Table 1). This is the key theoretical contribution of the present work. These theories imply that specific game elements or combinations thereof may be 
advantageous to learning under appropriate circumstances, but enhanced learning cannot generally be expected; as demonstrated by the present findings.

On a general level, the reasons for the present null results are most likely as follows. Some game elements might not increase (or might even decrease) motivation in the first place, as evidenced by no overall between-group differences in affective-motivational variables. Were motivation increased for a particular learner, the positive effect of motivation on enhanced cognitive processing (implied by the Cognitive-Affective Theory of Learning from Media) could be countered by increased distraction (predicted by the Cognitive Load Theory). Together, learning was not enhanced.

On the level of individual elements, the potential positive effects of a clear goal and increased choice (implied by SDT because of support for the need for competence and autonomy) could be countered by increased distraction due to the inevitable presence of extraneous details in the user interface of the gamified simulation. Also, the positive effects of choice in our gamified version might be quite subtle, because learners chose between solving tasks in the task-solving part. Solving tasks offered plenty of choices by itself (in all three comparison conditions) and thus also increased learners' feelings of autonomy.

Points were generally rated mildly positive, and thus they were probably not perceived by learners as controlling "expected tangible rewards" (which tend to undermine intrinsic motivation; according to SDT) but rather as informative feedback. However, learners could obtain feedback whenever they needed it by clicking on the "Assessment" button. The positive effect of points, like that of choice, was probably thus too subtle or countered by increased distraction. Because the simulation was for a single user, no negative interdependence, in the terms of Social Interdependence Theory, existed. Consequently, social-competitive pressure was minimal. Distraction was thus caused by the presence of user 
interface elements added to depict the number of achieved points and/or the learner's irrelevant thoughts related to the points.

Learners' also appreciated that there was an "appropriate" amount of praise, which means that praise also probably did not undermine intrinsic motivation (e.g., it could have been viewed by learners as childish). However, even though the praise contained learningrelated information, it might have brought little added value compared to control versions of the instructions. Its effect was again probably too subtle or countered by increased distraction.

\subsection{Practical and Methodological Implications}

A practical implication of this study (when also considering results from previous studies) is that one should be very cautious when gamifying an educational experience. The present findings mean that one should carefully think about which approach may work for the target audience in question and consider the pros and cons in his/her particular case. For instance, de-Marcos and colleagues (2016) showed that when a university course was augmented not only with game-based elements, but also a social platform, it was beneficial for the target audience. Also Sandberg and colleagues (2014) showed that combining a gamification approach with adaptive difficulty was beneficial for children in the case of a vocabulary learning application. Apparently, certain combinations of game-based elements, possibly with some non-game-based elements, can work in specific contexts. One should be careful when attempting to generalize the results of a study for different audiences: for instance, one may expect differential effects for different age groups (e.g., primary school children vs. adolescents vs. university learners). 
All of this also helps to highlight three methodological implications. First, gamification studies without control groups tend to report "promising" findings (Dicheva et al., 2015), while comparative studies (this one and studies reviewed in Section 2.1) deliver predominantly mixed/null results. This means that either the interpretation of the results of the former types of studies tends to be positively biased or that these studies use better gamification approaches compared to studies with control groups. The implication is that studies with control groups that would use ecologically valid interventions should start to dominate the research field. Second, it seems so far that large effect sizes cannot be automatically expected. Researchers should thus consider using larger samples. Third, researchers should also start considering participants' characteristics and educational contexts as moderating variables. Participants' age is not the only variable that may influence the outcomes (cf. Buckley et al., 2016). For instance, it seems reasonable that competitiveness (as a stable trait of participants; Houston et al., 2002; Harris and Houston, 2010) can moderate the effects of competition-based gamification approaches on both learning and affectivemotivational outcomes (cf. Brom et al., 2016). Another possible moderator, especially when considering digital learning materials, can be attitudes toward ICT (cf., e.g., Curtois et al., 2014). This study clearly showed that computer science students performed better and liked the learning experience more compared to other students (who might have less positive attitudes toward ICT). No significant study background $\times$ condition interaction was revealed, but this may be due to the small sample size. For much needed research on moderation effects, larger samples are also essential. When more results are available, findings may eventually uncover which gamification approaches (and when and for whom) are beneficial or detrimental in educational contexts. 


\subsection{Limitations}

This study is not without limitations. First, as already suggested, the study might miss a true effect due to its small sample size (which is, however, quite typical for an experimental, multimedia learning study, i.e., 30 per condition; cf., e.g., Fraenkel et al., 2012, p. 103). Second, we cannot exclude the possibility that some of our elements could have been implemented in a way that would have been more beneficial for learners. Third, because we investigated the combined effects of several game-based elements, we could have missed an individual element's effect due to the opposite effect of a different element. Methodological "purity" advises that we investigate the effects of individual elements. However, there is a trade-off between doing so and ecological validity. Looking at single game-based elements (e.g., in our case, assigning points without turning them into virtual currency at the end and without stating a clear game-like goal) may reduce the believability of the intervention in case of interconnected elements. This can artificially undermine intrinsic motivation. As a partial remedy, we asked participants about their opinions with respect to individual game-based elements. This is a practice we recommend. At the same time, too many game-based elements should not be combined in a single manipulation. We recommend focusing on "minimal sets" of these elements such that removing a single element would artificially reduce the believability of the intervention.

In our opinion, these limitations do not undermine this study's key findings: that neither beneficial nor detrimental effects of certain game-based elements on learning outcomes, initial interest, induced positive affect, flow, learning involvement and enjoyment were revealed. 


\subsection{Concluding Remarks}

Null results gained in this study generally corroborate earlier findings from comparative edu-gamification studies: that the alleged benefits of gamification in education are disputable and that one should be careful when gamifying educational methods or materials. This interim conclusion should be treated with caution, because comparative studies of edu-gamification approaches have thus far been few, and each of them used a somewhat different setting and/or gamification approach. Thus, their results may not be directly comparable, let alone broadly generalizable. The question how to gamify education and when (if at all) remains open. Theories introduced in our work (in Section 2.4) and their implications can assist researchers and designers in selecting the most promising game elements to be researched and eventually used. 


\section{Acknowledgement}

We thank research assistants who helped to conduct the experiments, most notably: V.

Dobrovolný, M. Stejskalová, K. Brožová. We also thank Laboratory of Behavioral and Linguistic Studies in Prague, where part of the study was conducted.

\section{Source of funding}

The first half of this study and pilots were primarily funded by Czech Grant Science Foundation (GA ČR) [grant number P407/12/P152]. The second study’s half was primarily funded by Czech Grant Science Foundation (GA ČR) [grant number 15-14715S]. Work of F. D. was supported by the Institute of Psychology, Academy of Sciences of the Czech Republic [grant number RVO 68081740].

\section{References}

Adams, D.M., Mayer, R.E., MacNamara, A., Koenig, A., Wainess, R., 2012. Narrative games for learning: Testing the discovery and narrative hypotheses. Journal of Educational Psychology 104, 235-249.

Anderson, A., Huttenlocher, D., Kleinberg, J., Leskovec, J., 2014. Engaging with Massive Online Courses, in: Proceedings of the 23rd International Conference on World Wide Web. ACM, pp. 687-698.

Barata, G., Gama, S., Jorge, J., Gonçalves, D., 2013. Improving Participation and Learning with Gamification, in: Proceedings of the First International Conference on Gameful Design, Research, and Applications. ACM, pp. 10-17. 
Brom, C., Bromová, E., Děchtěrenko, F., Buchtová, M., Pergel, M., 2014. Personalized messages in a brewery educational simulation: Is the personalization principle less robust than previously thought? Computers \& Education 72, 339-366.

Brom, C., Děchtěrenko, F., 2015. Mathematical Self-Efficacy as a Determinant of Successful Learning of Mental Models From Computerized Materials, in: ECGBL-9th European Conference on Games Based Learning. Academic Conferences and publishing limited, pp. 89-97.

Brom, C., Šisler, V., Slussareff, M., Selmbacherová, T., Hlávka, Z., 2016. You like it, you learn it: affectivity and learning in competitive social role play gaming. International Journal of Computer-Supported Collaborative Learning 11, 313-348.

Buckley, P., Doyle, E., O’Mahoney, A., 2016. Individualising Gamification: Investigating how Learning Styles Impact Upon Gamification, in: 10th European Conference on Games Based Learning: ECGBL 2016. Academic Conferences and Publishing International, pp. 82-88.

Cameron, J., Banko, K.M., Pierce, W.D., 2001. Pervasive negative effects of rewards on intrinsic motivation: The myth continues. The Behavior Analyst 24, 1-44.

Clark, D.B., Tanner-Smith, E.E., Killingsworth, S.S., 2016. Digital games, design, and learning a systematic review and meta-analysis. Review of educational research 86, $79-122$.

Clark, R.E., 2012. Learning from Media: Arguments, Analysis, and Evidence, Second Edition, 2nd. ed. Information Age Publishing.

Cohen, J., 1988. Statistical power analysis for the behavioral sciences, 2nd ed. Hillsdale, NJ: Erlbaum. 
Cordova, D.I., Lepper, M.R., 1996. Intrinsic motivation and the process of learning: Beneficial effects of contextualization, personalization, and choice. Journal of educational psychology $88,715-730$.

Courtois, C., Montrieux, H., De Grove, F., Raes, A., De Marez, L., Schellens, T., 2014. Student acceptance of tablet devices in secondary education: A three-wave longitudinal cross-lagged case study. Computers in Human Behavior 35, 278-286.

Darejeh, A., Salim, S.S., 2016. Gamification Solutions to Enhance Software User Engagement—A Systematic Review. International Journal of Human-Computer Interaction 32, 613-642.

de-Marcos, L., Domínguez, A., Saenz-de-Navarrete, J., Pagés, C., 2014. An empirical study comparing gamification and social networking on e-learning. Computers \& Education $75,82-91$.

de-Marcos, L., Garcia-Lopez, E., Garcia-Cabot, A., 2016. On the effectiveness of game-like and social approaches in learning: Comparing educational gaming, gamification \& social networking. Computers \& Education 95, 99-113.

Deci, E.L., Koestner, R., Ryan, R.M., 1999. A meta-analytic review of experiments examining the effects of extrinsic rewards on intrinsic motivation. Psychological Bulletin 125, 627-668.

Deci, E.L., Ryan, R.M., 1985. Intrinsic motivation and self-determination in human behavior. Plenum, New York.

Denny, P., 2013. The effect of virtual achievements on student engagement, in: Proceedings of the SIGCHI conference on human factors in computing systems. ACM, pp. 763772.

Deterding, S., Dixon, D., Khaled, R., Nacke, L., 2011. From Game Design Elements to Gamefulness: Defining "Gamification", in: Proceedings of the 15th international 
academic MindTrek conference: Envisioning future media environments. ACM, pp. $9-15$.

Dicheva, D., Dichev, C., Agre, G., Angelova, G., 2015. Gamification in education: a systematic mapping study. Educational Technology \& Society 18, 1-14.

Domínguez, A., Saenz-De-Navarrete, J., de-Marcos, L., Fernández-Sanz, L., Pagés, C., Martínez-Herráiz, J.-J., 2013. Gamifying learning experiences: Practical implications and outcomes. Computers \& Education 63, 380-392.

Fortier, M.S., Vallerand, R.J., Guay, F., 1995. Academic motivation and school performance: Toward a structural model. Contemporary educational psychology 20, 257-274.

Fraenkel, J.R., Wallen, N.E., Hyun, H.H., 2012. How to design and evaluate research in education, 8th ed. McGraw-Hill New York.

Garner, R., Brown, R., Sanders, S., Menke, D.J., 1992. "Seductive Details" and Learning from Text, in: The Role of Interest in Learning and Development, pp. 239-254.

Ginns, P., Martin, A.J., Marsh, H.W., 2013. Designing instructional text in a conversational style: a meta-analysis. Educational Psychology Review 25, 445-472.

Hakulinen, L., Auvinen, T., Korhonen, A., 2013. Empirical Study on the Effect of Achievement Badges in TRAKLA2 Online Learning Environment, in: Learning and Teaching in Computing and Engineering (LaTiCE), 2013. IEEE, pp. 47-54.

Halan, S., Rossen, B., Cendan, J., Lok, B., 2010. High score!-motivation strategies for user participation in virtual human development, in: International Conference on Intelligent Virtual Agents. Springer, pp. 482-488.

Hamari, J., 2017. Do badges increase user activity? A field experiment on the effects of gamification. Computers in human behavior 71, 469-478. 
Hamari, J., Koivisto, J., Sarsa, H., 2014. Does Gamification Work? - A Literature Review of Empirical Studies on Gamification, in: 47th Hawaii International Conference on System Sciences. IEEE, pp. 3025-3034.

Hanus, M.D., Fox, J., 2015. Assessing the effects of gamification in the classroom: A longitudinal study on intrinsic motivation, social comparison, satisfaction, effort, and academic performance. Computers \& Education 80, 152-161.

Harris, P.B., Houston, J.M., 2010. A reliability analysis of the revised competitiveness index. Psychological reports 106, 870-874.

Hattie, J., Timperley, H., 2007. The power of feedback. Review of Educational Research 77, 81-112.

Heidig, S., Clarebout, G., 2011. Do pedagogical agents make a difference to student motivation and learning? Educational Research Review 6, 27-54.

Houston, J., Harris, P., McIntire, S., Francis, D., 2002. Revising the competitiveness index using factor analysis. Psychological Reports 90, 31-34.

Isen, A.M., Reeve, J., 2005. The influence of positive affect on intrinsic and extrinsic motivation: Facilitating enjoyment of play, responsible work behavior, and selfcontrol. Motivation and Emotion 29, 295-323.

Johnson, D.W., Johnson, R.T., 1989. Cooperation and competition: Theory and research. Interaction Book Company, Edina, MN.

Johnson, D.W., Johnson, R.T., 2009. An educational psychology success story: Social interdependence theory and cooperative learning. Educational researcher 38, 365-379.

Katz, B., Jaeggi, S., Buschkuehl, M., Stegman, A., Shah, P., 2014. Differential effect of motivational features on training improvements in school-based cognitive training. Frontiers in human neuroscience 8, 242. 
Ke, F., 2008. Computer games application within alternative classroom goal structures: cognitive, metacognitive, and affective evaluation. Educational Technology Research and Development 56, 539-556.

Landers, R.N., Callan, R.C., 2011. Casual Social Games as Serious Games: The Psychology of Gamification in Undergraduate Education and Employee Training, in: Serious Games and Edutainment Applications. Springer, pp. 399-423.

Levy, K.J., 1980. A Monte Carlo study of analysis of covariance under violations of the assumptions of normality and equal regression slopes. Educational and Psychological Measurement 40, 835-840.

Mayer, R.E., 2009. Multimedia Learning, 2nd ed. Cambridge University Press.

Mayer, R.E., 2014. Computer Games for Learning: An Evidence-Based Approach. The MIT Press.

McGonigal, J., 2011. Reality is Broken: Why Games Make us Better and How They Can Change the World. Penguin.

Moreno, R., 2005. Instructional technology: Promise and pitfalls, in: Technology-based education: Bringing researchers and practitioners together. Information Age Publishing, pp. 1-19.

Morschheuser, B., Hamari, J., Koivisto, J., 2016. Gamification in crowdsourcing: A review, in: Proceedings of 49th Hawaii International Conference on System Sciences, pp. $4375-4384$.

Morschheuser, B., Hamari, J., Werder, K., Abe, J., 2017. How to gamify? A method for designing gamification, in: Proceedings of the 50th Hawaii International Conference on System Sciences, pp. 1298-1307.

Park, B., Flowerday, T., Brünken, R., 2015. Cognitive and affective effects of seductive details in multimedia learning. Computers in Human Behavior 44, 267-278. 
Patall, E.A., Cooper, H., Robinson, J.C., 2008. The effects of choice on intrinsic motivation and related outcomes: a meta-analysis of research findings. Psychological Bulletin $134,270-300$.

Plass, J.L., Heidig, S., Hayward, E.O., Homer, B.D., Um, E., 2014. Emotional design in multimedia learning: Effects of shape and color on affect and learning. Learning and Instruction 29, 128-140.

Plass, J.L., O'Keefe, P.A., Homer, B.D., Case, J., Hayward, E.O., Stein, M., Perlin, K., 2013. The Impact of Individual, Competitive, and Collaborative Mathematics Game Play on Learning, Performance, and Motivation. Journal of Educational Psychology 105, 1050-1066.

Qin, Z., Johnson, D.W., Johnson, R.T., 1995. Cooperative versus competitive efforts and problem solving. Review of Educational Research 65, 129-143.

R Core Team, 2017. A language and environment for statistical computing. R Foundation for Statistical Computing, Vienna, Austria. available: http://www.R-project.org/ [Accessed 15 August 2017]

Rheinberg, F., 2004. Motivationsdiagnostik [Motivation diagnosis]. Gottingen: Hogrefe Rheinberg, F., Vollmeyer, R., Burns, B.D., 2001. FAM: Ein Fragebogen zur Erfassung aktueller Motivation in Lern-und Leistungssituationen [QCM: A questionnaire to assess current motivation in learning situations]. Diagnostica 47, 57-66.

Rheinberg, F., Vollmeyer, R., Engeser, S., 2003. Die Erfassung des Flow-Erlebens [in German], in: Steinsmeier-Pelster, J., Rheinberg, F. (Eds.), Diagnostik von Motivation und Selbstkonzept. Hogrefe, pp. 261-279.

Sandberg, J., Maris, M., Hoogendoorn, P., 2014. The added value of a gaming context and intelligent adaptation for a mobile learning application for vocabulary learning. Computers \& Education 76, 119-130. 
Schraw, G., Bruning, R., Svoboda, C., 1995. Sources of situational interest. Journal of Literacy Research 27, 1-17.

Stevens, J.P., 2012. Applied multivariate statistics for the social sciences. Routledge.

Suresh, K., 2011. An overview of randomization techniques: an unbiased assessment of outcome in clinical research. Journal of human reproductive sciences 4, 8-11. van Roy, R., Zaman, B., 2017. Why Gamification Fails in Education-And How to Make it Successful: Introducing Nine Gamification Heuristics Based on Self-Determination Theory, in: Ma, M., Oikonomou, A. (Eds.), Serious Games and Edutainment Applications, Volume II. Springer International Publishing AG, pp. 485-509. Wang, A.I., Zhu, M., Sætre, R., 2016. The Effect of Digitizing and Gamifying Quizzing in Classrooms, in: 10th European Conference on Games Based Learning: ECGBL 2016. Academic Conferences and Publishing International, pp. 729-737.

Watson, D., Clark, L.A., Tellegen, A., 1988. Development and validation of brief measures of positive and negative affect: the PANAS scales. Journal of personality and social psychology 54, 1063-1070.

Wilensky, U. (1999) NetLogo, Center for Connected Learning and Computer-Based Modeling, Northwestern University, available: http://ccl.northwestern.edu/netlogo/ [accessed 14.8.2017].

Wouters, P., van Nimwegen, C., van Oostendorp, H., van der Spek, E.D., 2013. A MetaAnalysis of the Cognitive and Motivational Effects of Serious Games. Journal of Educational Psychology 105, 249-265. 